\title{
CARBONACEOUS COMPOUNDS IN COMETS: INFRARED OBSERVATIONS
}

\author{
T. ENCRENAZ \\ Observatoire de Paris \\ DESPA, URA 264 \\ 92195 Meudon, \\ France \\ R. KNACKE \\ Astronomy Program, Department of Earth and Space Sciences, \\ State University of New York, Stony Brook \\ Current Address: ES-63, NASA Marshall Space Flight Center \\ Huntsville, Alabama 35812 USA
}

\begin{abstract}
The Comet Halley observations showed that carbon is a major component of the comet nucleus, with mass spectroscopic data giving near-cosmic $\mathrm{C} / \mathrm{O}$ ratios. Gaseous and solid compounds were also observed with infrared spectroscopy, which gave detections of $\mathrm{CO}$ and $\mathrm{C}_{2} \mathrm{O}_{2}$, probable detections or upper limits of $\mathrm{H}_{2} \mathrm{CO}$ and $\mathrm{CH}_{4}$, and a tentative detection of OCS. The $\mathrm{CH}_{4} / \mathrm{CO}$ ratio of less than unity in Comet Halley points to a CO-rich solar nebula; however, the ratio is higher than in interstellar clouds. A broad, complicated emission feature near $3.4 \mu \mathrm{m}$ is evidence for carbonaceous compounds containing $\mathrm{C}-\mathrm{H}$ groups in gas or solid phases. Analysis of radiation mechanisms and abundance constraints suggests that thermal emission or transient heating by single photons can account for the 3.4- $\mu \mathrm{m}$ emission feature. The band resembles (but is not identical to) bands of carbonaceous chondrite organic material, synthetic materials, and interstellar carbonaceous bands. Direct connections among these materials are possible, but have not been established.
\end{abstract}

\section{Introduction}

Carbon plays a fundamental role in chemical and physical processes in the solar system. Carbon's place as the fourth most abundant element, its complex chemistry including both refractory and volatile compounds, and its pivotal role in biology combine to make carbon a key to many diverse problems. Therefore, a particularly gratifying result of the Comet Halley campaigns is that a significantly better, but by no means complete, understanding of carbon in comets has emerged.

In equilibrium, methane and carbon monoxide are described by the net reaction 


$$
\mathrm{CH}_{4}+\mathrm{H}_{2} \mathrm{O} \rightarrow \mathrm{CO}+\mathrm{H}_{2}
$$

At low temperatures, methane and water dominate, while above several hundred degrees, the balance shifts to $\mathrm{CO}$ and $\mathrm{H}_{2}$. Methane dominates in the atmospheres of the giant planets, which are cold and strongly reducing. A case that is far from equilibrium is the interstellar gas, where carbon monoxide is second only in abundance to $\mathrm{H}_{2}$ and the abundance ratio of $\mathrm{CH}_{4} / \mathrm{CO}$ is less than 0.01 (Irvine and Knacke 1989). Another case, according to recent theoretical investigations, was the solar nebula, where non-equilibrium processes could have caused $\mathrm{CO}$ to be the dominant gaseous carbon species (Lewis and Prinn 1980).

The gas is not the whole story, however. In typical molecular clouds, $\mathrm{CO}$ accounts for only $10 \%-15 \%$ of the cosmic abundances of carbon. Most of the rest of the carbon is almost surely in interstellar dust particles. There is evidence that grains, including carbonaceous matter, survived in the solar nebula (Kerridge and Chang 1985).

Since comets are primitive objects and possible probes of the early solar system, the role of carbon in them is particularly important in a number of subjects. The Comet Halley studies showed that comets are rich in carbonaceous material, with the total $\mathrm{C} / \mathrm{O}$ ratio near the cosmic ratio (Jessberger et al. 1989). What can cometary carbon tell us about conditions in the early solar system and the interstellar dust? In what gaseous and solid forms did carbon occur? Are carbonaceous materials in comets, meteorites, interplanetary particles, and interstellar dust related?

The focus of this paper is on reviewing the present understanding derived from infrared observations of carbonaceous compounds in comets . Mass spectroscopy, with many important results for carbon chemistry, is the subject of a review by Jessberger (1990) in this volume. We discuss infrared spectral signatures and emission mechanisms of simple gaseous molecules and of complex molecules and grains. We then review current interpretations of cometary infrared spectra, including identifications, abundances, and comparisons of cometary carbonaceous spectra and the spectra of carbonaceous chondrites, interstellar dust, and synthetic compounds. Finally, we suggest some future observations and directions.

\section{Overview of Observations}

A spectrum of Comet Halley taken by the IKS-VEGA spectrometer shown in Figure 1 (Combes et al. 1988) illustrates the kind of spectral data that were derived from the Halley studies. The 2- to 5 - $\mu \mathrm{m}$ spectral region is especially useful for investigation of molecules, because resonant fluorescent excitation is efficient there (Section 3.1). The spectrum consists of a series of emission bands superimposed on a background continuum. The strongest band is the $\mathrm{H}_{2} \mathrm{O} \nu 3$ feature at $2.7 \mu \mathrm{m}$ (Mumma et al. 1986; Combes et al. 1986). Several molecular spectral signatures are marked and will be discussed below. Except for the feature denoted "C-H", these are fluorescent excitations of gaseous species. The C-H fea- 
ture has not been identified in detail, but evidence suggests that it is mainly emission by solid particles containing carbon-hydrogen groups (Section 4.3). In addition to the spacecraft results, numerous ground-based and airborne spectra were obtained, including some at higher resolution and extending to longer wavelengths (Section 4.1). Carbon-bearing molecules $\left(\mathrm{HCN}, \mathrm{CH}_{4}\right.$, and $\left.\mathrm{CO}_{2}\right)$ were also detected by spectroscopy at other wavelengths and/or by mass spectroscopy. A cometary molecule is probably a parent if its density distribution varies as $r^{-2}$, with $\mathrm{r}$ being the distance from the nucleus. The number of molecules in the line of sight then varies as $r^{-1}$, and increases linearly with the field of view centered on the nucleus. These properties of the gas coma follow from simple models which have generally been confirmed by in situ measurements made by the space probes (Combes et al. 1988). From such observations, $\mathrm{H}_{2} \mathrm{O}$ and $\mathrm{CO}_{2}$, and possibly $\mathrm{H}_{2} \mathrm{CO}$ and OCS, were identified as parents. $\mathrm{CN}$ is a secondary product. $\mathrm{CO}$ appears to be both a parent and a daughter (Section 3.3.7).

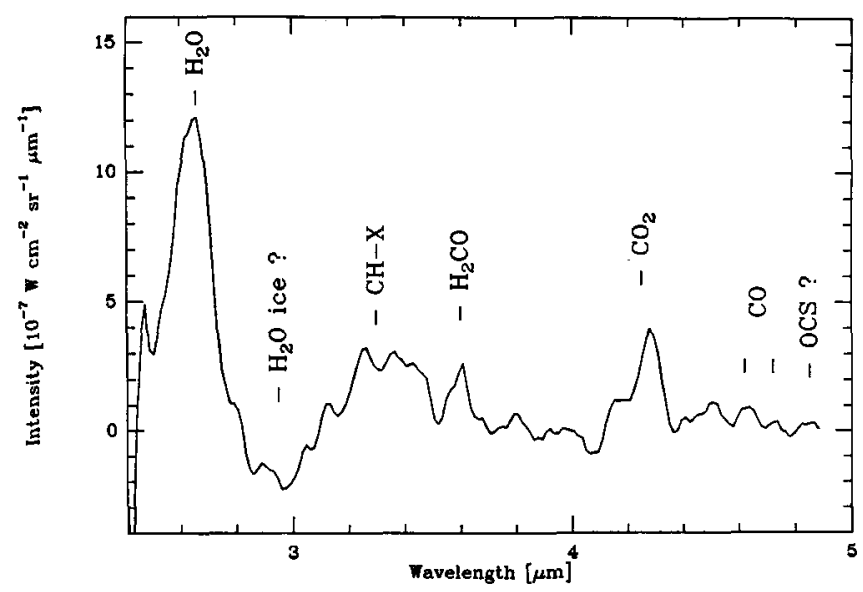

Figure 1. The spectrum of Comet Halley between 2.5 and $5 \mu \mathrm{m}$. The spectrum was obtained from the average of five individual spectra taken with IKS-VEGA when the spacecraft was near 42,000 $\mathrm{km}$ from the nucleus (Combes et al. 1988).

The first infrared spectrum of a comet was obtained in 1966 with observations of IkeyaSeki 1965 f (Becklin and Westphal 1966); later, notable results were of Comet Bennett 1969i (Maas et al. 1970) and Kohoutek $1973 f$ (Gatley et al. 1974; Ney 1982). Mainly broad-band photometry was obtained, which showed a blackbody-like thermal continuum and identified emissions near 10 and $18 \mu \mathrm{m}$. Recent photometric results are reviewed by Hanner and Tokunaga (1990) in this volume. Before Halley, sensitivities were high enough to obtain 2to $5-\mu \mathrm{m}$ spectra at resolving powers of $\mathrm{R}=50$ of few objects, notably comets West $1975 \mathrm{n}$ (Oishi et al. 1978), and Comet IRAS-Araki-Alcock 1983d (Hanner et al. 1985). Much of our knowledge about the organic material has accrued since the Comet Halley apparition. 


\section{Simple Gaseous Molecules}

\subsection{RESONANT SCATTERING}

Early attempts to model cometary infrared spectra were made by Yamamoto (1982), who pointed out that the main excitation mechanism is resonant scattering (also called resonant fluorescence) of solar radiation. This analysis was confirmed by Encrenaz et al. (1982) and by Crovisier and Encrenaz (1983), who investigated emission by 20 candidate molecules through direct IR excitation, by solar flux scattered by dust and the nucleus, and by dust thermal radiation. It was found that direct solar flux is the main excitation mechanism, with resonant fluorescence being most efficient in the 2- to $5-\mu \mathrm{m}$ range. Below $2 \mu \mathrm{m}$, the intrinsic intensities of the molecular bands (overtone and combination bands) tend to decrease; above $5 \mu \mathrm{m}$, the intensity of the solar blackbody emission becomes too low. Table 1 summarizes some plausible cometary parent molecules, the spectral bands where they may be detectable, and the band strengths.

The resonant fluorescent flux of a molecular band can be estimated as follows (Crovisier and Encrenaz 1983). The pumping rate, $g$, is

$$
g=\Omega / 4 \pi \times A\left[e^{h c \sigma / k T}-1\right]^{-1}
$$

where $\Omega$ is the solid angle of the solar radiation field and $\mathrm{T}$ is its temperature. $\sigma$ is the frequency of the molecular band center in $\mathrm{cm}^{-1}$, and $\mathrm{A}$ is the spontaneous emission Einstein coefficient. In terms of the band strength, $S$, in cm-Amagat, $A$ is

$$
A=3.89 \times 10^{-8} \sigma^{2} S
$$

The flux emitted in the molecular band is then

$$
\phi=h c \sigma g N
$$

with $\mathrm{N}$ being the number of molecules in the field of view.

The energy received by a ground-based telescope from a molecular band has been calculated by Haser (1957), Keller and Lillie (1974), and Yamamoto (1982), assuming pure fluorescence emission. Calculations have been extended to in situ (spacecraft) observations and to more complex excitation mechanisms by Crovisier and Encrenaz (1983) and Weaver and Mumma (1984). For a telescope located at a distance D from the nucleus, the integrated band flux is (Combes et al. 1988) 
Table 1. Positions and strengths of infrared bands of carbon-bearing molecules from Crovisier and Encrenaz (1983).

\begin{tabular}{|c|c|c|c|c|c|c|}
\hline Molecule & $\begin{array}{c}\text { Photo- } \\
\text { dissocia- } \\
\text { tion Rate, } \\
s^{-1} \\
\end{array}$ & $\begin{array}{l}\text { Refer- } \\
\text { ence }\end{array}$ & Band Identification & $\begin{array}{l}\text { Frequency, } \\
\qquad \mathrm{cm}^{-1}\end{array}$ & $\begin{array}{c}\text { Strength, } \\
\mathrm{cm}^{-1} \\
\mathrm{~atm}^{-1}\end{array}$ & $\begin{array}{c}\Delta v \\
(F W H M) \\
c m^{-1}\end{array}$ \\
\hline $\mathrm{C}_{2} \mathrm{H}_{4}$ & $4.8(-5)$ & $\begin{array}{c}a, 2,3 \\
2,3 \\
2,3 \\
2,3 \\
2,3 \\
2,3 \\
2,3 \\
2,3 \\
2,3\end{array}$ & $\begin{array}{c}v_{4} \\
v_{7} \\
v_{10} \\
v_{12} \\
v_{7}+v_{8} \\
v_{6}+v_{10} \\
v_{3}+v_{10} \\
v_{11} \\
v_{9}\end{array}$ & $\begin{array}{c}825 \\
949 \\
995 \\
1443 \\
1889 \\
2047 \\
2325 \\
2989 \\
3105\end{array}$ & $\begin{array}{c}- \\
150 \\
- \\
60 \\
20 \\
3 \\
1.5 \\
\}_{100}\end{array}$ & $\begin{array}{c}- \\
100 \\
- \\
100 \\
150 \\
100 \\
100 \\
\}_{200}\end{array}$ \\
\hline $\mathrm{C}_{2} \mathrm{H}_{2}$ & $3.1(-5)$ & $\begin{array}{c}a, 1,3 \\
1,3 \\
3 \\
3 \\
3 \\
1,3 \\
1,3 \\
3 \\
3\end{array}$ & $\begin{array}{c}v_{5} \\
v_{4}+v_{5} \\
2 v_{4}+v_{5} \\
3 v_{5} \\
v_{2}+v_{5} \\
v_{3} \\
v_{2}+v_{4}+v_{5} \\
v_{2}+2 v_{4}+v_{5} \\
v_{3}+v_{4}\end{array}$ & \begin{tabular}{|c|}
730 \\
1328 \\
1956 \\
2215 \\
2701 \\
3287 \\
3294 \\
3881 \\
3897
\end{tabular} & $\begin{array}{c}700 \\
90 \\
3 \\
3 \\
8 \\
\}_{300} \\
\}_{10}\end{array}$ & $\begin{array}{c}100 \\
100 \\
- \\
- \\
\}_{150}^{150} \\
\}_{100}\end{array}$ \\
\hline OCS & & $\begin{array}{l}1 \\
1\end{array}$ & $\begin{array}{l}v_{1} \\
v_{3}\end{array}$ & $\begin{array}{r}859 \\
2062 \\
\end{array}$ & $\begin{array}{c}60 \\
2400 \\
\end{array}$ & - \\
\hline $\mathrm{C}_{2} \mathrm{H}_{6}$ & & $\begin{array}{l}2,3 \\
2,3 \\
2,3 \\
2,3 \\
2,3 \\
2,3 \\
2,3 \\
2,3 \\
2,3 \\
2,3 \\
2,3 \\
2,3 \\
2,3 \\
2,3 \\
2,3 \\
3\end{array}$ & $\begin{array}{c}v_{9} \\
v_{6} \\
v_{4}+v_{12} \\
v_{8} \\
2 v_{12}, v_{2}+v_{9} \\
v_{9}+v_{11} \\
v_{3}+v_{6} \\
v_{3}+2 v_{9} \\
v_{2}+v_{6} \\
v_{8}+11 \\
v_{5}, v_{7} \\
v_{6}+2 v_{9} \ldots \\
v_{8}+2 v_{9} \\
v_{2}+v_{3}+v_{9} \ldots \\
v_{3}+v_{9}+v_{11 . .}\end{array}$ & $\begin{array}{c}820 \\
1379 \\
1414 \\
1486 \\
2230 \\
2302 \\
2368 \\
2660 \\
2753 \\
2894 \\
2954,2994 \\
3006 \\
3100-3150 \\
3185 \\
3222 \\
\sim 3700\end{array}$ & $\begin{array}{l}\}^{20} 40 \\
\}_{3}^{1.5} \\
\}_{4} \\
\}_{90} \\
\}_{4} \\
2\end{array}$ & 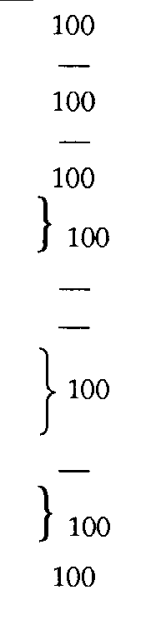 \\
\hline $\mathrm{CO}$ & $6.5(-7)$ & $a, 1,3$ & $1-0$ & 2143 & 230 & 150 \\
\hline
\end{tabular}


Table 1. (continued)

\begin{tabular}{|c|c|c|c|c|c|c|}
\hline Molecule & $\begin{array}{c}\text { Pboto- } \\
\text { dissocia- } \\
\text { tion Rate, } \\
s^{-1}\end{array}$ & $\begin{array}{l}\text { Refer- } \\
\text { ence }\end{array}$ & Band Identification & $\begin{array}{l}\text { Frequency, } \\
\qquad \mathrm{cm}^{-1}\end{array}$ & $\begin{array}{c}\text { Strengtb, } \\
\mathrm{cm}^{-1} \\
\mathrm{~atm}^{-1}\end{array}$ & $\begin{array}{c}\Delta v \\
(F W H M) \\
c m^{-1}\end{array}$ \\
\hline $\mathrm{CH}_{4}$ & $7.7(-6)$ & $\begin{array}{c}a, 1,3 \\
1,3 \\
2,3 \\
2,3 \\
2,3 \\
1,3\end{array}$ & $\begin{array}{c}v_{4} \\
v_{2} \\
v_{3}-v_{4} \\
2 v_{4} \\
v_{2}+v_{4} \\
v_{3}\end{array}$ & $\begin{array}{l}1306 \\
1534 \\
1720 \\
2600 \\
2823 \\
3019\end{array}$ & $\begin{array}{c}150 \\
2 \\
- \\
- \\
\sim 10 \\
275\end{array}$ & $\begin{array}{l}150 \\
150 \\
- \\
- \\
200 \\
200\end{array}$ \\
\hline $\mathrm{HCN}$ & $1.3(-5)$ & $\begin{array}{c}a, 1,3 \\
1,3 \\
1,3 \\
2,3 \\
2,3 \\
1,3\end{array}$ & $\begin{array}{c}v_{2} \\
2 v_{2} \\
v_{1} \\
3 v_{2} \\
v_{1}+v_{2} \\
v_{3}\end{array}$ & $\begin{array}{c}712 \\
1412 \\
2097 \\
2116 \\
2800 \\
3311\end{array}$ & $\begin{array}{c}200 \\
\}^{45} \\
\sim 3 \\
240\end{array}$ & \}$^{100} \begin{array}{l}150 \\
\sim 100 \\
100 \\
150\end{array}$ \\
\hline $\mathrm{H}_{2} \mathrm{CO}$ & $2.8(-4)$ & $\begin{array}{c}\mathrm{a}, 1,3 \\
1,3 \\
1,3 \\
1,3 \\
1,3 \\
1,3 \\
1,3 \\
1,3\end{array}$ & $\begin{array}{l}v_{4} \\
v_{6} \\
v_{3} \\
v_{2} \\
v_{1} \\
v_{5} \\
2 v_{3} \\
2 v_{2}\end{array}$ & $\begin{array}{l}1167 \\
1249 \\
1500 \\
1743 \\
2783 \\
2843 \\
2973 \\
2472\end{array}$ & $\begin{array}{c}\}_{40} \\
37 \\
237 \\
519 \\
15\end{array}$ & $\begin{array}{l}- \\
\overline{1} \\
100 \\
100 \\
\}_{200} \\
100\end{array}$ \\
\hline $\mathrm{CO}_{2}$ & $2.0(-6)$ & $\begin{array}{c}a, 1 \\
1,3 \\
1 \\
1 \\
1 \\
1 \\
1 \\
1 \\
1 \\
1,3 \\
1 \\
1 \\
1 \\
1,3 \\
1,3 \\
\end{array}$ & $\begin{array}{c}3 v_{2}-2 v_{2} \\
v_{2} \\
2 v_{2}-v_{2} \\
v_{1}-v_{2} \\
v_{1}+v_{2}-2 v_{2} \\
v_{3}-v_{1} \\
v_{3}-2 v_{2} \\
3 v_{2} \\
v_{1}+v_{2} \\
v_{3} \\
5 v_{2}+v_{3}-3 v_{2} \\
4 v_{2}+v_{3}-2 v_{2} \\
3 v_{2}+v_{3}-v_{2} \\
2 v_{2}+v_{3} \\
v_{1}+v_{3}\end{array}$ & $\begin{array}{c}647 \\
667 \\
668 \\
721 \\
742 \\
961 \\
1064 \\
1934 \\
2077 \\
2349 \\
3543 \\
3553 \\
3580 \\
3613 \\
3715 \\
\end{array}$ & $\begin{array}{c}1 \\
194 \\
30 \\
8 \\
0.2 \\
0.02 \\
0.03 \\
0.03 ? \\
0.14 \\
2500 \\
0.01 \\
0.07 \\
2 \\
30 \\
40 \\
\end{array}$ & $\begin{array}{l}- \\
100 \\
- \\
- \\
- \\
- \\
- \\
- \\
- \\
100 \\
- \\
- \\
- \\
\sim 100 \\
\sim 100 \\
\end{array}$ \\
\hline
\end{tabular}


Table 1. (continued)

\begin{tabular}{|c|c|c|c|c|c|c|}
\hline Molecule & $\begin{array}{c}\text { Pboto- } \\
\text { dissocia- } \\
\text { tion Rate, } \\
s^{-1} \\
\end{array}$ & $\begin{array}{l}\text { Refer- } \\
\text { ence }\end{array}$ & Band Identification & $\begin{array}{l}\text { Frequency, } \\
\qquad \mathrm{cm}^{-1}\end{array}$ & $\begin{array}{c}\text { Strength, } \\
\mathrm{cm}^{-1} \\
\mathrm{~atm}^{-1}\end{array}$ & $\begin{array}{c}\Delta v \\
(F W H M) \\
c m^{-1}\end{array}$ \\
\hline$\left(\mathrm{CH}_{3}\right)_{2} \mathrm{O}$ & $1.2(-4)$ & $\begin{array}{c}\mathrm{b}, 2,3 \\
2,3 \\
2,3 \\
2,3 \\
2 \\
2 \\
2\end{array}$ & $\begin{array}{c}v_{6} \\
v_{17} \\
v_{5,10,16,20} \\
v_{3,4,9,14,15,19} \\
v_{7}+v_{16}, v_{7}+v_{20} \\
v_{3}+v_{7}, v_{4}+v_{7} . . \\
v_{3}+v_{12}, v_{4}+v_{21} \ldots \\
v_{6}+v_{17} \\
v_{6}+\ldots \\
2 v_{15}, v_{12,13,18} \\
\end{array}$ & $\begin{array}{c}920,940 \\
1102,1122 \\
1180 \\
1466 \\
1605 \\
1861 \\
2032 \\
2100 \\
2399 \\
2914 \\
\end{array}$ & $\begin{array}{c}100 \\
200 \\
300 \\
100 \\
7 \\
2 \\
\}^{2} \\
7 \\
300 \\
\end{array}$ & $\begin{array}{l}175 \\
50 \\
50 \\
75 \\
- \\
- \\
- \\
- \\
- \\
-150\end{array}$ \\
\hline $\mathrm{CH}_{3} \mathrm{OH}$ & $2.7(-4)$ & $\begin{array}{c}\mathrm{a}, 2,3 \\
2,3 \\
2,3 \\
2,3 \\
2,3 \\
2,3 \\
2,3 \\
2,3 \\
2,3 \\
\end{array}$ & $\begin{array}{c}v_{4} \\
v_{4}+v_{8} \\
v_{8} \\
v_{3} \\
2 v_{4} \\
v_{2} \\
v_{5} \\
v_{1} \\
\end{array}$ & $\begin{array}{c}1040 \\
1209 \\
1260 \\
1340 \\
1455,1477 \\
2053 \\
2844 \\
2977 \\
3682 \\
\end{array}$ & $\begin{array}{l}\sim 600 \\
- \\
- \\
\sim 120 \\
\sim 800 \\
\sim 120 \\
-\end{array}$ & $\begin{array}{c}100 \\
\}-200 \\
200 \\
200 \\
- \\
\end{array}$ \\
\hline $\mathrm{C}_{2} \mathrm{H}_{5} \mathrm{OH}$ & & $\begin{array}{l}3 \\
3 \\
3 \\
3 \\
3\end{array}$ & & $\begin{array}{r}880 \\
1050 \\
1250 \\
1400 \\
2950 \\
\end{array}$ & $\begin{array}{c}70 \\
400 \\
120 \\
150 \\
300 \\
\end{array}$ & $\begin{array}{c}50 \\
75 \\
75 \\
75 \\
100 \\
\end{array}$ \\
\hline $\mathrm{CS}_{2}$ & $1.0(-2)$ & $c, 1$ & $\begin{array}{c}v_{3} \\
v_{1}+v_{3} \\
2 v_{3} \\
\end{array}$ & $\begin{array}{l}1535 \\
2183 \\
2319 \\
\end{array}$ & $\begin{array}{c}2300 \\
- \\
- \\
\end{array}$ & $\begin{array}{l}- \\
- \\
-\end{array}$ \\
\hline $\mathrm{CH}_{3} \mathrm{NH}_{2}$ & $6.6(-4)$ & $\begin{array}{c}\mathrm{b}, 3,4 \\
3,4 \\
3,4 \\
3,4 \\
3,4\end{array}$ & $\begin{array}{c}v_{9} \\
v_{8} \\
v_{13} \\
v_{4} \\
v_{2}-v_{11}\end{array}$ & $\begin{array}{c}780 \\
1044 \\
1455 \\
1623 \\
2961-2985\end{array}$ & $\begin{array}{c}500 \\
100 \\
40 \\
40 \\
160\end{array}$ & $\begin{array}{c}50 \\
100 \\
100 \\
100 \\
200\end{array}$ \\
\hline
\end{tabular}

References for photodissociation rates
a - Huebner and Carpenter (1979).
b - Jackson (1976).
c - Jackson et al. (1982).
d - Controverted.

References for spectral lines

1 - Pugh and Rao (1976).

2 - Herzberg (1945).

3 - Pierson et al. (1956).

4 - Lecomte (1958).

5 - Murphy (1970).

6 - Burch et al. (1963).

7 - Catalano et al. (1963). 


$$
W=h c \sigma g Q /(4 \pi \theta v D)
$$

where $\mathrm{Q}$ is the production rate of the molecule (in $\mathrm{s}^{-1}$ ), $\theta$ is the angular field of view, and $v$ is the expansion velocity of the molecule (assumed constant). The formula is valid if the linear field of view, $\mathrm{D}$, is much smaller than the molecular scale-length, typically between $10^{3}$ and $10^{5} \mathrm{~km}$.

Detailed calculations of emission spectra have been completed for several molecules: CO (Crovisier and Le Bourlot 1983; Chin and Weaver 1984); HCN and CN-bearing molecules (Bockelee-Morvan et al. 1984); $\mathrm{H}_{2} \mathrm{O}$ (Crovisier 1984; Bockelee-Morvan and Crovisier 1987; Bockelee-Morvan 1987; Bisikalo et al. 1987). Crovisier (1987) calculated the emission by several linear molecules $\left(\mathrm{CO}, \mathrm{CO}_{2}, \mathrm{HCN}, \mathrm{HC}_{3} \mathrm{~N}, \mathrm{C}_{2} \mathrm{~N}_{2}\right.$, and $\left.\mathrm{OCS}\right)$ in their rotation lines and strongest vibration bands.

\subsection{INDIVIDUAL MOLECULES}

3.2.1 $\mathrm{CO}_{2}$. The presence of carbon dioxide in comets had been suspected since the detection of $\mathrm{CO}_{2}^{+}$ion in the tail of Comet Bester 1947k (Swings and Page 1950) and several subsequent comets (A'Hearn and Feldman 1980). It was also anticipated from theoretical models of cometary and interstellar chemistry (Huebner et al. 1982).

The $\mathrm{CO}_{2}$ molecule was unambiguously detected in Comet Halley through its $4.25-\mu \mathrm{m} \nu_{3}$ vibration band in the IKS-VEGA spectrum (Combes et al. 1986; Moroz et al. 1987). The derived mixing ratio $\left(\mathrm{CO}_{2} / \mathrm{H}_{2} \mathrm{O}\right)$ at a heliocentric distance of $0.8 \mathrm{AU}$ was $(2.7 \pm 0.3) \times 10^{-2}$ (Combes et al. 1988). The carbon dioxide detection was corroborated by the neutral mass spectrometer experiment, which detected a peak at 44 AMU (Krankowsky et al. 1986). The mixing ratio derived from the NMS (Neutral Mass Spectrometer) result is in substantial agreement with that from the infrared, if one subtracts about $30 \%$ of the NMS signal as being due to compounds of the same mass (e.g., $\mathrm{CS}, \mathrm{C}_{3} \mathrm{H}_{8}$ ).

Carbon dioxide is therefore an important minor constituent of the cometary nucleus. Since its vaporization rate is a factor of two greater than that of water (Delsemme 1982), it could be at least partly responsible for early cometary activity, detected as far as $8 \mathrm{AU}$ in Halley (Le Fevre et al. 1984). Feldman et al. (1986) suggested that it might also be responsible for outbursts at smaller heliocentric distances.

3.2.2 $\mathrm{H}_{2} \mathrm{CO}$. Formaldehyde was considered as a possible compound in cometary nuclei and included in models long before its detection (Giguere and Huebner 1978; Biermann et al. 1982). It was identified by its $\nu_{1}(3.59 \mu \mathrm{m})$ and $\nu_{5}(3.51 \mu \mathrm{m})$ vibrational bands in the IKS-VEGA data (Moroz et al. 1987; Combes et al. 1988). It was also identified, although more tentatively, in ground-based spectra taken about six weeks after perihelion (Knacke et al. 1986; Danks et al. 1987), but was not convincingly detected in other ground-based spectra taken after this date (Wickramasinghe and Allen 1986; Baas et al. 1986). This 
could imply a variation in the $\mathrm{H}_{2} \mathrm{CO}$ production rate as a function of heliocentric distance, or could just be a problem of $\mathrm{S} / \mathrm{N}$ ratios. Mumma and Reuter (1989) suggested that the $\mathrm{H}_{2} \mathrm{CO}$ peaks may be correlated with the photometric periodicity curve of Comet Halley . The data of March 1986 give a formaldehyde mixing ratio of 0.04 of the abundance of $\mathrm{H}_{2} \mathrm{O}$ (Combes et al. 1988). This is probably an upper limit, because the spectral region may be contaminated by other $\mathrm{C}-\mathrm{H}$ bearing molecules.

Two other observations corroborate the formaldehyde detection. First, $\mathrm{H}_{2} \mathrm{CO}$ with a mixing ratio of $0.015-0.025$ was discovered in the radio at $4.8 \mathrm{GHz}$ (Snyder et al. 1989). Second, there is a proposed identification of polymerized formaldehyde in spectra obtained with the Giotto heavy ion mass spectrometer (Mitchell et al. 1987; Huebner 1987; Huebner et al. 1987). However, the $\mathrm{H}_{2} \mathrm{CO}$ observed with the IKS-VEGA experiment has a parent molecule distribution and seems to be directly outgassed from the nucleus rather than from polyoxymethylene ("POM") grains. It is possible that $\mathrm{H}_{2} \mathrm{CO}$ polymers, for which there is a small shift of the central wavelengths of the vibrational bands, might be responsible for the complicated structure in Halley infrared spectra.

Recent higher-resolution spectra of Comet Wilson 19861 are not consistent with formaldehyde as the sole source of the structure in the 3-to 4- $\mu \mathrm{m}$ spectral region (Brooke et al. 1989). Either the features are not formaldehyde after all, or other compounds also contribute to the structure.

3.2.3 OCS. OCS was tentatively identified at $4.85 \mu \mathrm{m}$ in the IKS-VEGA data (Combes et al. 1988). The corresponding production rate (or upper limit) is less than 0.01 that of water. An upper-limit mixing ratio of 0.06 was derived from a radio search (Bockelee-Morvan et al. 1987). The amount of OCS that can be present is definitely insufficient to account for the total amount of sulfur, assuming a sulfur mixing ratio of 0.02 (Azoulay and Festou 1986). Possible sulfur-containing parents include $S_{2}$ and CS. $S_{2}$ was detected in Comet IRAS-Araki-Alcock 1983d (A'Hearn et al. 1983) and possibly in Comet Halley (Kim and A'Hearn 1989). CS has been detected in several comets (Feldman 1982). The mixing ratios of $S_{2}$ and CS are only of order 0.001 , so sulfur should be present in other parent molecules or grains.

3.2.4 HCN. Like formaldehyde, HCN had been suspected for some time in comets and was tentatively detected in the millimeter range in Comet Kohoutek 1973f (Huebner et al. 1974). Unambiguous identifications at $88.6 \mathrm{GHz}$ were obtained in Comet Halley (Despois et al. 1986; Bockelee-Morvan et al. 1987; Schloerb et al. 1987). The mixing ratio is close to 0.001 of the abundance of $\mathrm{H}_{2} \mathrm{O}$. This value, compared with observed $\mathrm{CN}$ mixing ratios, suggests that $\mathrm{HCN}$ is a major parent of $\mathrm{CN}$ but probably not the only one (Schloerb et al. 1987). The abundance of $\mathrm{HCN}$ would not be detectable in existing infrared spectra.

3.2.5 $\mathrm{CH}_{4}$.Methane was long suspected to be a major compound in cometary nuclei, although Delsemme (1982) had expressed a contrary view. If methane were abundant, its $\nu 3$ band at $3.3 \mu \mathrm{m}$ should have been detectable in Comet Halley. In fact, the $\mathrm{CH}_{4}$ molecule was not detected, although a broad emission was found between 3.2 and $3.5 \mu \mathrm{m}$ (Section 4.1). An upper limit of 0.04 for the $\mathrm{CH}_{4} / \mathrm{H}_{2} \mathrm{O}$ mixing ratio was measured with high-resolution 
airborne spectroscopy (Drapatz et al. 1987). Kawara et al. (1989) reported a marginal detection or upper limit corresponding to a mixing ratio of about 0.01 . Methane was also searched for with the Giotto neutral mass spectrometer, resulting in an upper limit mixing ratio of 0.07 (Krankowsky et al. 1986). Allen et al. (1987) derived a $\mathrm{CH}_{4}$ mixing ratio of 0.02 from ion mass spectrometer data. Recently, Larson et al. (1989) reported a possible detection (3-sigma) of methane in Comet Wilson (19861), with mixing ratio between 0.014 and 0.045 . The mixing ratio is in the Halley range of estimates and upper limits.

3.2.6 $\mathrm{CH}_{3} \mathrm{C} N$. This molecule was tentatively identified at $110.67 \mathrm{GHz}$ in Comet Kohoutek 1973f (Ulich and Conklin 1975). However, $\mathrm{CH}_{3} \mathrm{CN}$ was not detected in Comet Halley, where an upper-limit mixing ratio of $10^{-3}$ was obtained (Bockelee-Morvan et al. 1987).

3.2.7 $\mathrm{CO}$. $\mathrm{CO}^{+}$has been seen in comet tails for some decades. Neutral carbon monoxide was discovered in Comet West (1975n) in the ultraviolet and has been seen in several more recent comets (see the review by Wyckoff 1982). The abundance of CO varies considerably among comets, but the reason for this is not well understood.

Before the Comet Halley observations, there was considerable uncertainty about the origin of $\mathrm{CO}$, particularly about whether $\mathrm{CO}$ is a parent or daughter. A partial resolution has come from observations of Halley with the space probes. Values of $\mathrm{CO} / \mathrm{H}_{2} \mathrm{O}=0.10-0.20$ (Festou et al. 1986) and 0.17 (Woods et al. 1986) were derived from UV observations using large apertures. In contrast, the Giotto NMS found that within about $1000 \mathrm{~km}$ from the nucleus, the mixing ratio was less than 0.07 . Farther out, the mixing ratio actually increased with distance up to a value of 0.24 at $20,000 \mathrm{~km}$ (Eberhardt et al. 1987). The near-nucleus result was confirmed by the IKS-VEGA infrared spectrum, which gave a mixing ratio of $\mathrm{CO} / \mathrm{H}_{2} \mathrm{O}=0.05$ for the parent component of $\mathrm{CO}$. Thus $\mathrm{CO}$ effuses both from the nucleus as a parent and from an extended source in the coma. The coma source is probably dust from which either $\mathrm{CO}$ molecules or very short-lived parents evolve.

\section{Complex Molecules and Grains}

\subsection{OBSERVATIONS OF 3.3- TO 3.5- $\mu \mathrm{m}$ EMISSION}

The "C-H" feature in Figure 1 must originate in more complex compounds than the molecules discussed above. The width, intensity, and structure of the band suggest that at least several and perhaps many species are involved. Note that the equivalent width of the feature is on the same order as that of the $\mathrm{H}_{2} \mathrm{O}$ emission; that is, the feature at $3.4 \mu \mathrm{m}$ apparently comes from something fairly abundant, if the emission mechanism is the same as for $\mathrm{H}_{2} \mathrm{O}$ (although see Section 4.2.3). A complicated feature such as this at the $\mathrm{C}-\mathrm{H}$ fundamental stretch frequency near $3.4-\mu \mathrm{m}$ is characteristic of organic compounds, because of carbon's tendency to form diverse compounds incorporating $\mathrm{C}-\mathrm{H}$ groups.

Shortly after the discovery of the 3.4- $\mu$ m emission by IKS-VEGA, the feature was ob- 
served by several ground-based teams (Allen and Wickramasinghe 1986, Knacke et al. 1986, Danks et al. 1986; Baas et al. 1986; see Fig. 2). Subsequently, it was also seen in Comet Wilson 19861 (Brooke et al. 1989; Allen and Wickramasinghe 1987), Bradfield 1987s (Brooke et al. 1989) and Brorsen-Metcalf 1989o. A comparison of the feature in three comets is shown in Figure 3 (Brooke and Tokunaga 1990). The bands near $3.4 \mu \mathrm{m}$ are strikingly similar in comets Halley, Wilson, and Bradfield. The spectra all show distinct peaks near 3.36 and $3.52 \mu \mathrm{m}$, and possibly one near $3.29 \mu \mathrm{m}$, evidently signatures of molecular functional groups. How much more detail is present is not yet clear. The present highestresolution observations $(\lambda / \Delta \lambda=400-800)$ may not reveal all the structure (Baas et al. 1986; Brooke et al. 1989).

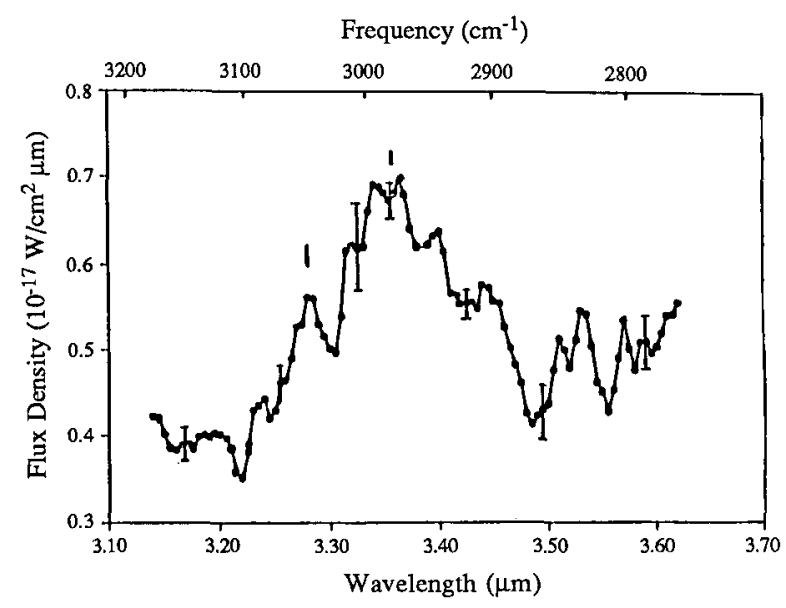

Figure 2. The spectrum of P/Halley recorded by Baas et al. (1987). The 3.28- $\mu \mathrm{m}$ emission (attributed to unsaturated/aromatics hydrocarbons) and the 3.36- $\mu \mathrm{m}$ emission (attributed to saturated hydrocarbons) are clearly visible.

The resemblance of the 3.4- $\mu \mathrm{m}$ emissions in three comets (Figure 3) must mean that they contain a rather uniform complement of organic compounds. Indeed, the features vary less than those of compounds synthesized in laboratory simulations of organic processing (Greenberg 1982). Natural organics such as kerogens and coals show characteristic spectra, but with considerable variations in the $3.4-\mu \mathrm{m}$ band also (Rouxhet et al. 1980). The infrared data suggest that organics in comets are products of similar processing histories.

Since Wilson and Bradfield were new comets and Halley is old, processes affecting only nuclear surface layers are unlikely to be the reason for the uniform carbonaceous composition. For example, cosmic ray irradiation of ices can produce organic compounds. By current estimates, the cosmic rays could process up to $10 \mathrm{~m}$ of a comet nucleus fresh from the Oort Cloud (Chyba and Sagan 1987a). Halley-like comets would lose most of this material in a few perihelion passages, yet Comet Halley has passed by the sun hundreds of times. 
A simpler explanation is that the organics were incorporated when comets formed. Organic compounds would then be distributed throughout the nuclei as the observations indicate. This is evidence that comets do preserve primitive carbonaceous material, possibly including material from interstellar grains (Brooke et al. 1989).

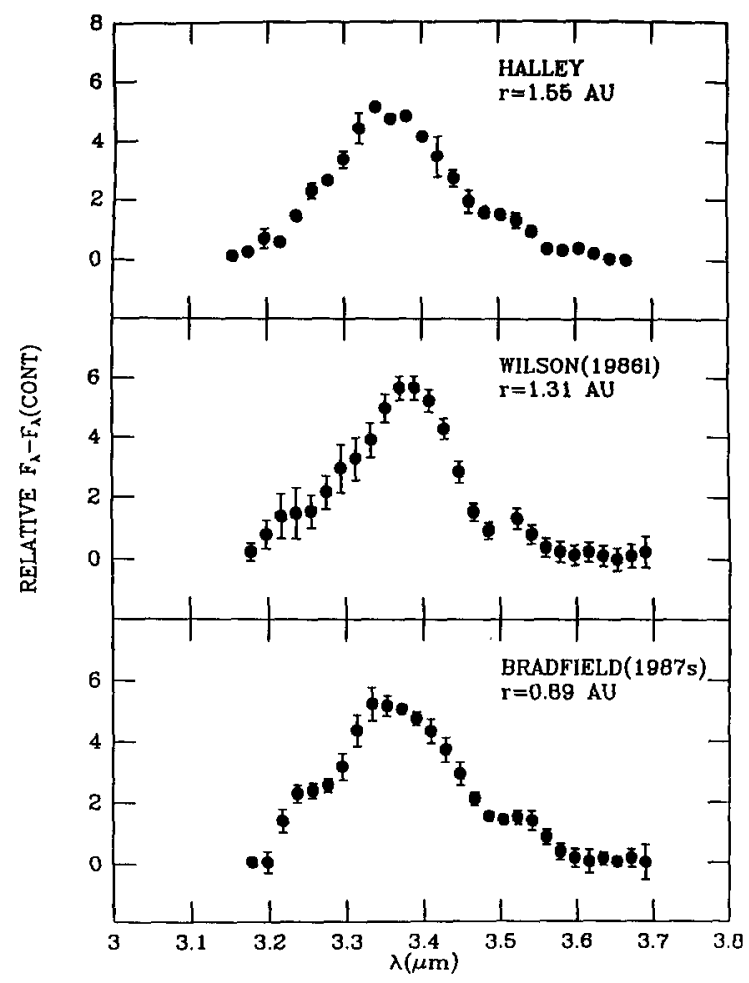

Figure 3. Spectra of comets Halley, Wilson, and Bradfield near $3.4 \mu \mathrm{m}$. The areas (equivalent widths) of the bands were normalized to emphasize the structure and shapes of the features (Tokunaga and Brooke 1990).

\subsection{GRAIN EMISSION MECHANISMS}

In addition to the resonance fluorescence described above, two grain mechanisms have been proposed to account for the 3.3- to $3.4-\mu \mathrm{m}$ emission observed in comets: small particle thermal emission (Knacke et al. 1986) and ultraviolet pumped fluorescence (Baas et al. 


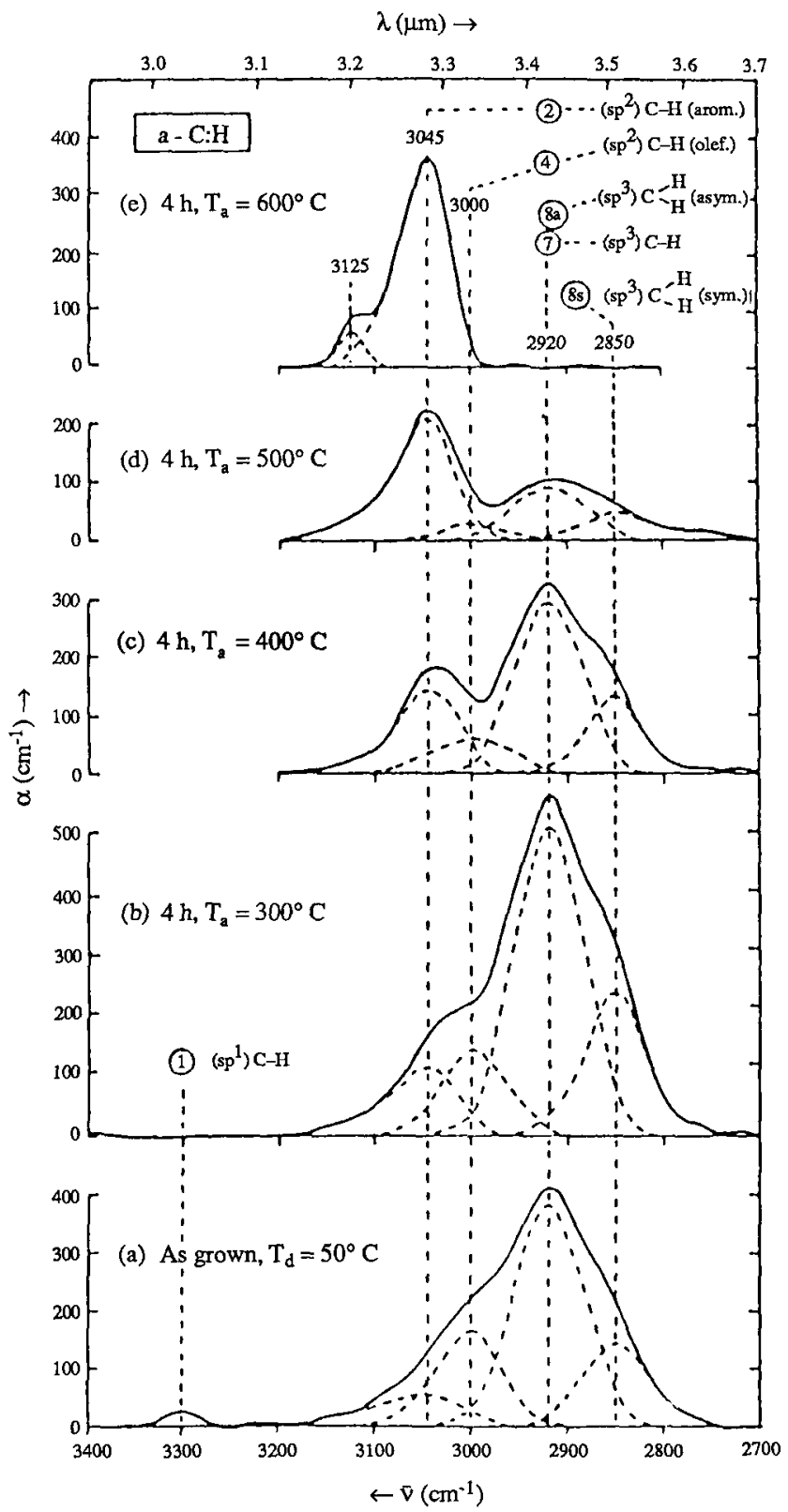

Figure 4. Normalized $\mathrm{C}-\mathrm{H}$ stretch absorption spectra for a-C:H coatings on germanium. (a) as grown (b)-(e) annealed as indicated. Deconvolutions of overlapping bands and assignments are shown by broken lines (Dischler et al. 1983). 
1986).

4.2.1 Thermal Enission by Small Cometary Grains. Several authors have modeled thermal emission by small cometary grains between 2 and $20 \mu \mathrm{m}$ (Knacke et al. 1986; Chyba and Sagan 1987a; Greenberg and Zhao 1988; Krishna Swamy et al. 1988). Band emission is strongly dependent upon the temperatures and sizes of the grains. According to the laboratory extinction curve of amorphous carbon measured by Koike et al. (1980), grains $1 \mu \mathrm{m}$ or larger would radiate like blackbodies, since the single grain optical depth would be larger than about 5 . This means that only small grains, with a diameter of about 0.1 $\mu \mathrm{m}$ or less, will show significant emission features above the blackbody continuum (which is due to large grains).

The production rate Q of C-H groups is given by (Knacke et al. 1986; Encrenaz et al. 1988)

$$
Q=2 v \Delta^{2} F / \pi s B(T) S
$$

where $\mathrm{F}$ is the integrated flux in the band, $v$ is the grain velocity, $\mathrm{S}$ is the integrated band strength, $\mathrm{B}(\mathrm{T})$ is the blackbody function at the corresponding wavelength, $\mathrm{s}$ is the radius of the observed coma area, and $\Delta$ is the geocentric distance. The temperature, $T$, of the grains at a given heliocentric distance, $R$, can be estimated from their size (Hanner et al. 1985 ). For typical observing conditions at $\mathrm{R}=1 \mathrm{AU}$, the temperature of $0.1 \mu \mathrm{m}$ absorbing grains can reach $400-600 \mathrm{~K}$, but is strongly dependent on grain composition.

When the formula is applied to the 3.4- $\mu \mathrm{m}$ emission band, one finds that the dust thermal emission is very much more efficient than resonance fluorescence. With reasonable values for the $\mathrm{C} / \mathrm{C}-\mathrm{H}$ ratio, thermal emission by small grains requires only a few percent of the carbon abundance required for resonant fluorescence.

4.2.2 Transient Heating by UV Photons. This mechanism was suggested by Baas et al. (1986) in analogy with grain heating process proposed to account for interstellar emission features observed near HII regions (Sellgren 1984). Large molecules or angstrom sized particles are episodically heated by single UV photons. For a 50-atom molecule/particle, the temperature reaches $1000 \mathrm{~K}$, and the corresponding emission peaks around $3 \mu \mathrm{m}$.

Assuming, following Baas et al. (1986) a g-factor of $0.2 \mathrm{~s}^{-1}$ at $\mathrm{R}=1 \mathrm{AU}$, one can estimate the production rate of such large molecules. As in the case of thermal emission by small grains, the $\mathrm{C}$ abundance required is very low, about a few percent of that required for the fluorescence mechanism (Encrenaz et al. 1988). However, the quantitative details are quite uncertain. 
4.2.3 Abundances Implied by the 3.4- $\mu \mathrm{m}$ Band. As pointed out above, the integrated intensity of the 3.2-to 3.5- $\mu \mathrm{m}$ band is large, comparable to that of the total $\mathrm{H}_{2} \mathrm{O}$ emission at 2.7 $\mu \mathrm{m}$ (Figure 1). With the inefficient resonant fluorescence mechanism, this causes difficulties with the amount of carbon and cosmic abundances requirements (Knacke et al. 1986). In detailed analyses of the VEGA spectra, Combes et al. (1988) and Encrenaz et al. (1988) showed that the amount of carbon involved is very high, more than $50 \%$ of the number of $\mathrm{H}_{2} \mathrm{O}$ molecules. This result would imply that all the cometary carbon would have to be in the form of gaseous hydrocarbons (assuming a cosmic $\mathrm{C} / \mathrm{O}$ ratio of 0.5 ). Since we know from the spacecraft mass spectrometers that carbon is also present in cometary grains, this is an unrealistic result. On the contrary, the PUMA/PIA experiment found that $80 \%$ or more of the carbon is in solid form, and less than $20 \%$ is gaseous (Jessberger et al. 1989; Jessberger 1990).

Table 2. Carbon and Oxygen abundances of parent molecules in $\mathrm{P} / \mathrm{Halley}$

\begin{tabular}{|c|c|c|c|c|}
\hline \multirow{2}{*}{$\begin{array}{l}\text { Molecular } \\
\text { species }\end{array}$} & \multirow{2}{*}{$\begin{array}{c}\text { Relative } \\
\text { abundance } \\
\text { (rel. to } \mathrm{H}_{2} \mathrm{O}\end{array}$} & \multicolumn{2}{|c|}{ Relative atomic abundance } & \multirow[t]{2}{*}{ Reference } \\
\hline & & $\mathrm{O}$ & $\mathrm{C}$ & \\
\hline $\mathrm{H}_{2} \mathrm{O}$ & 1 & 1 & & \\
\hline $\mathrm{CO}_{2}$ & $0.03 \pm 0.01$ & $0.06 \pm 0.02$ & $0.03 \pm 0.01$ & Combes et al. (1988) \\
\hline $\mathrm{H}_{2} \mathrm{CO}$ & $0.04 \pm 0.02$ & $0.04 \pm 0.02$ & $0.04 \pm 0.02$ & $\begin{array}{l}\text { Combes et al. (1988) } \\
\text { Snyder et al. (1989) }\end{array}$ \\
\hline $\mathrm{CO}$ & $0.05 \pm 0.02$ & $0.05 \pm 0.02$ & $0.05 \pm 0.02$ & $\begin{array}{l}\text { Combes et al. (1988) } \\
\text { Eberhardt et al. (1988) }\end{array}$ \\
\hline OCS & $0.007 \pm 0.003$ & $0.007 \pm 0.003$ & $0.007 \pm 0.003$ & Combes et al. (1988) \\
\hline $\mathrm{HC}, \mathrm{N}$ & $0.001 \pm 0.005$ & & $0.001 \pm 0.0005$ & Bockelee-Morvan et al. (1988) \\
\hline $\mathrm{CH}_{4}$ & $0.02 \pm 0.01$ & & $0.02 \pm 0.01$ & Allen et al. (1987) \\
\hline TOTAL & & $1.157 \pm 0.063$ & $0.148 \pm 0.0635$ & \\
\hline
\end{tabular}

By summing all the known carbon parent molecules and comparing them with the PUMA/PIA abundances, one can determine the relative amounts of gaseous and solid carbon remaining to account for the 3.3- to 3.4- $\mu \mathrm{m}$ feature. A compilation is given in Table 2. This compilation shows that taking into account the carbon-bearing parent molecules already detected, the ratio of gaseous carbon to gaseous oxygen is about 0.12 . We also have to account for the oxygen trapped in the dust. Assuming a cosmic abundance value for silicium, magnesium etc., we derive a value of 0.10 for the ratio of gaseous $C$ to the total $O$ in Comet Halley. This is actually an upper limit, as some oxygen is trapped in the grains, too (Jessberger et al. 1990). On the other hand, the carbon measurement obtained from the dust mass spectrometry measurement implies that $C_{\text {gas }} / O_{\text {total }}$ has to be 0.10 or less. This implies that the amount of gaseous hydrocarbons in Comet Halley has to be negligible. Taking into account the error bars in Table 2 and the uncertainty of Jessberger's result, we 
derive that, in any case, the gaseous hydrocarbons cannot account for more than $30 \%$ of the total carbon. As a consequence, most of the 3.2- to 3.5- $\mu \mathrm{m}$ feature, if not all, has to come from small cometary grains and/or large molecules (PAH, QCC...).

There is some uncertainty in the derivation of abundances from intensities of these vibration bands (Combes et al. 1988). We have to know the number of stretches and the number of atoms in the various cases. For saturated hydrocarbons (alkanes), mostly composed of $\mathrm{CH}_{2}$ chains, we can reasonably assume $\mathrm{C} / \mathrm{C}-\mathrm{H}=\mathrm{C} / \mathrm{H}=0.5$. For alkenes, $\mathrm{C} / \mathrm{C}-\mathrm{H}$ is close to 1 , but for alkynes, the $\mathrm{C} / \mathrm{C}-\mathrm{H}$ ratio can become very large in large molecules. In aromatics, the $\mathrm{C} / \mathrm{C}-\mathrm{H}$ ratio is typically in the range 1 to 3 (Bellamy 1975; Leger and d'Hendecourt 1987). The absence of 3.0- to $3.2-\mu \mathrm{m}$ features probably implies that double and triple bonds are not very abundant in comets (Section 4.3 ), so the $\mathrm{C} / \mathrm{C}-\mathrm{H}$ ratio is probably not much larger than 3 . However, one has to keep in mind that the uncertainty in the $\mathrm{C} / \mathrm{C}-\mathrm{H}$ ratio induces a large uncertainty in carbon abundances derived solely from the 3.4- $\mu \mathrm{m}$ feature.

We emphasize that these mechanisms can be so efficient that the amount of carbon required to give the emission can be as low as only a few percent of the total carbon abundance. Of course, lower grain temperatures resulting from size or albedo effects could increase the required amount of carbon. Alternatively, significant amounts of carbon might be present in other forms, undetectable at $3 \mu \mathrm{m}$, such as large grains or graphitic compounds.

\subsection{3- TO 3.4- $\mu \mathrm{m}$ SPECTRAL ANALYSIS}

Infrared bands in the 3- to $4-\mu \mathrm{m}$ spectral region are often difficult to interpret, because the $\mathrm{C}-\mathrm{H}$ absorptions are so ubiquitous in organic compounds. Neighbouring atoms and local molecular structure determine the exact positions of infrared bands. Their superposition gives features in many substances that approximately resemble the comet emission. The identification problem is somewhat different from that for gaseous molecules, because it is no longer feasible to identify complicated species exactly by infrared spectroscopy. The emission features mainly characterize groups or linkages within the molecules rather than specifying the detailed structure.

In Table 3, we list frequencies of some common $\mathrm{C}-\mathrm{H}$ groups and compare them with those of cometary bands (Bellamy 1975; Colangeli et al. 1989). The table is far from complete; discussions of other possibly important bands such as alcohols, carbynes, etc... may be found in the literature (Bellamy 1975). Figure 4 shows the appearance of superposed bands of different structural groups (Dischler et al. 1983). Note how annealing produces more stable aromatic groups.

The portion of the comet band peaking near $3.36 \mu \mathrm{m}$ matches alkanes (single carbon bonds or saturated compounds) reasonably well. $\mathrm{CH}_{3}$ group vibrations occur at $3.37 \mu \mathrm{m}$ and $3.48 \mu \mathrm{m}$ aud $\mathrm{CH}_{2}$ group vibrations occur at 3.42 and $3.50 \mu \mathrm{m}$. Comparisons among the table and Figures 1 to 4 will probably convince the reader that a good case can be made for 
superpositions of these bands in the comet spectra. Bands of the less saturated compounds usually fall below $3.34 \mu \mathrm{m}$ (Table 3 ). The absence of strong cometary features between 3.0 and $3.2 \mu \mathrm{m}$ implies that double or triple bonds are not very abundant in comet organics.

TABLE 3. Functional Group Frequencies

\begin{tabular}{lccc} 
Bond Type & Wavelength ${ }^{1}$ & $\begin{array}{c}\text { Nearest } \\
\text { Comet Band }\end{array}$ & $\begin{array}{c}\text { Nearest } \\
\text { Interstellar Band }\end{array}$ \\
\hline Alkynes & & & \\
CH & $3.017 \pm .005$ & & \\
Alkenes & & & \\
$=\mathrm{CH}$ & $3.242 \pm .008$ & & \\
-CH=CH- & $3.306 \pm .017$ & & \\
= CH & $3.316 \pm .016$ & & $3.29^{2}$ \\
Aromatic & & & \\
$=\mathrm{CH}$ & $3.290 \pm .010$ & 3.29 & $3.38^{3}$ \\
Alkanes & & & \\
$\mathrm{CH}$ (asym) & $3.376 \pm .012$ & 3.34 & \\
$\mathrm{CH}_{2}$ (asym) & $3.418 \pm .012$ & & \\
$\mathrm{CH}^{3}$ & $3.460 \pm .012$ & overlapping (?) \\
$\mathrm{CH}_{3}$ (sym) & $3.482 \pm .012$ & 3.483 & \\
$\mathrm{CH}_{2}$ (sym) & $3.505 \pm .012$ & 3.52 & \\
\hline
\end{tabular}

1 Bellamy (1975)

${ }^{2}$ Interstellar Emission in HII regions

${ }^{3}$ Interstellar Absorption to the Galactic Center (IRS 7) (Butchart et al. 1987)

There is also some structure near $3.29 \mu \mathrm{m}$ (Figures 1 and 2). This is the position of a very characteristic aromatic, or ring molecule, carbon band (Baas et al. 1986). Compare, for example, (b) and (c) in Figure 4. Supporting evidence for ring compounds comes from the probable detection of $\mathrm{C}_{3} \mathrm{H}_{3}^{+}$in the Halley coma (Korth et al. 1989).

In our view, a reasonable interpretation is that the 3.3- to $3.4-\mu \mathrm{m}$ feature contains spectral signatures of $-\mathrm{CH}_{2}$ and $-\mathrm{CH}_{3}$ groups and an aromatic component, but not much is known about the overall structures of the materials in which these functional groups are located.

\subsection{OTHER INFRARED BANDS}

Vibration-rotation spectra of molecules and solids usually contain many bands between 4 and $15 \mu \mathrm{m}$. Indeed, these are usually more diagnostic than the complicated, overlapping bands in the 3- to 4- $\mu \mathrm{m}$ region. Table 1 lists vibrations that may eventually be observable 
in the infrared spectral range between 2 and $30 \mu \mathrm{m}$ (Crovisier and Encrenaz 1983).

There are only weak indications for long wavelength emissions in comets at the present time. The reason for this was pointed out by Chyba and Sagan (1987a). At wavelengths longward of $4 \mu \mathrm{m}$, the dust thermal emission continuum tends to dominate the spectrum. Narrow dust emission features have intensities of only a few percent of the continuum and would be difficult to observe with present sensitivities. The feature to continuum contrast depends on heliocentric distance and could become an investigative tool when better sensitivities are achieved (Chyba et al. 1989).

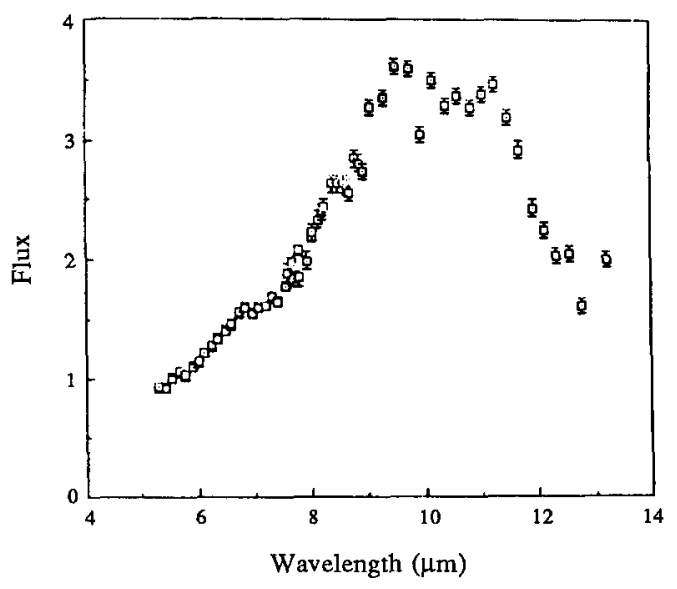

Figure 5. The 5-13 $\mu \mathrm{m}$ spectrum of the central condensation of comet Halley taken on December 12.1 and 17.2 UT. Note the structure suggesting a band near $6.8 \mu \mathrm{m}$. The 8 - to $12-\mu \mathrm{m}$ spectral region contains silicate emissions (Bregman et al., 1987).

The best case for a carbonaceous feature in the intermediate infrared is a weak emission band near $6.8 \mu \mathrm{m}$, as seen in Figure 5 (Campins et al. 1986; Bregman et al. 1987). The band is marginally present in the IKS-VEGA spectra also (Combes et al. 1988). Bregman et al. suggest that the band could be $\mathrm{C}-\mathrm{H}$ deformation vibrations or carbonate emission. Since resonance fluorescence is ineffective at these wavelengths, thermal or UV excited emission by small particles are the most likely mechanisms.

Several weak spectral features await confirmation in bright comets. Structure at 3.8 and $4.0 \mu \mathrm{m}$ (Figure 1) could be related to some transitions in solids. An interesting interpretation of a marginally detected feature at $4.45 \mu \mathrm{m}$ is that it might be the signature of $\mathrm{C} \equiv \mathrm{N}$ in small grains. However, the band occurs nearer $4.6 \mu \mathrm{m}$ in laboratory spectra (d'Hendecourt et al. 1986). These questions are still open, but the interpretation of the 3.3to $3.4-\mu \mathrm{m}$ feature in terms of thermal emission by small grains suggests that the process may also be acting for weaker features. 


\subsection{OTHER EVIDENCE FOR CARBONACEOUS GRAINS IN COMETS}

Several independent lines of evidence for carbonaceous material have come from the exploration of Halley. The images of the nucleus from Giotto (Keller et al. 1986) and VEGA (Sagdeev et al. 1986) show that it has a very low albedo, suggesting absorbing carbonaceous material on the surface. The dark crust is consistent with earlier infrared measurements suggesting very dark grains (Hanner et al. 1985). Low albedos and high temperatures were inferred for the nuclei of comets IRAS-Araki-Alcock (1983d) (Hanner et al. 1985) and P/Arend-Rigaux (1984k) (Brooke and Knacke 1986; Millis et al. 1988). The high temperature (more than $400 \mathrm{~K}$ ) measured by the IKS-VEGA at the subsolar point of the nucleus (Emerich et al. 1987) strongly suggests the presence of inactive nuclear regions and a dark crust.

Measurements by the VEGA and Giotto dust mass spectrometers demonstrated the presence of small grains predominantly composed of $\mathrm{C}, \mathrm{H}, \mathrm{O}$, and $\mathrm{N}$ (Kissel et al. 1986; Clark et al. 1987). Further interpretation of these data also suggests the presence of heavy compounds with multiple bonds (Kissel and Krueger 1987). The distribution of $\mathrm{C}_{2}$ and $\mathrm{CN}$ radicals implies that these secondary compounds originate, at least partly, in hydrocarbon grains (A'Hearn et al. 1986). The same mechanism has been invoked to explain CO abundances (Section 3.3.7).

It seems likely that the CHON grains are responsible for the infrared emissions observed in the $3-\mu \mathrm{m}$ region and possibly at $6.8 \mu \mathrm{m}$. These grains could vaporize to produce hydrocarbon gaseous molecules that may also contribute to the $3-\mu \mathrm{m}$ emission.

\section{Interpretation}

\subsection{THE $\mathrm{CH}_{4} / \mathrm{COO}$ RATIO}

Since $\mathrm{CO}$ freezes around 25 to $30 \mathrm{~K}$, the discovery of $\mathrm{CO}$ emanating from the Halley nucleus was first thought to show that cometary nuclei formed at very low temperatures and large heliocentric distances. Recently, however, Sandford and Allamandola (1988) found that CO condenses on $\mathrm{H}_{2} \mathrm{O}$ surfaces at temperatures up to $50 \mathrm{~K}$. This temperature is more typical of the Uranus-Neptune zone.

The result that there is more carbon monoxide than methane in the Halley nucleus seems conclusive. The $\mathrm{CO} / \mathrm{CH}_{4}$ ratio is certainly greater than 1.7 , and perhaps considerably higher. The ratio is significant evidence that $\mathrm{CO}$ rather than $\mathrm{CH}_{4}$ dominated the solar nebula (Allen et al. 1987). Therefore it now appears that the reduction of $\mathrm{CO}$ to $\mathrm{CH}_{4}$ was quenched in the solar nebula, as proposed in the Lewis and Prinn (1980) models. Analyses 
of the ice/rock ratios in outer solar system objects support this result (Johnson et al. 1987).

About $10 \%$ to $15 \%$ of the carbon is in CO in typical molecular clouds (although higher fractions occur in Orion, Scoville et al. 1983). In the gas phase in dense molecular clouds, $\mathrm{CO} / \mathrm{CH}_{4}>100$ (Knacke et al. 1988). New observations indicate there is little solid methane either (Allamandola 1988). Thus, while in both comets and the interstellar gas, a significant fraction of the carbon bonds is in $\mathrm{CO}$, there is relatively much more methane in Comet Halley. The Comet Halley ices evidently do not preserve unaltered gas phase abundances of molecular clouds (Allen et al. 1987).

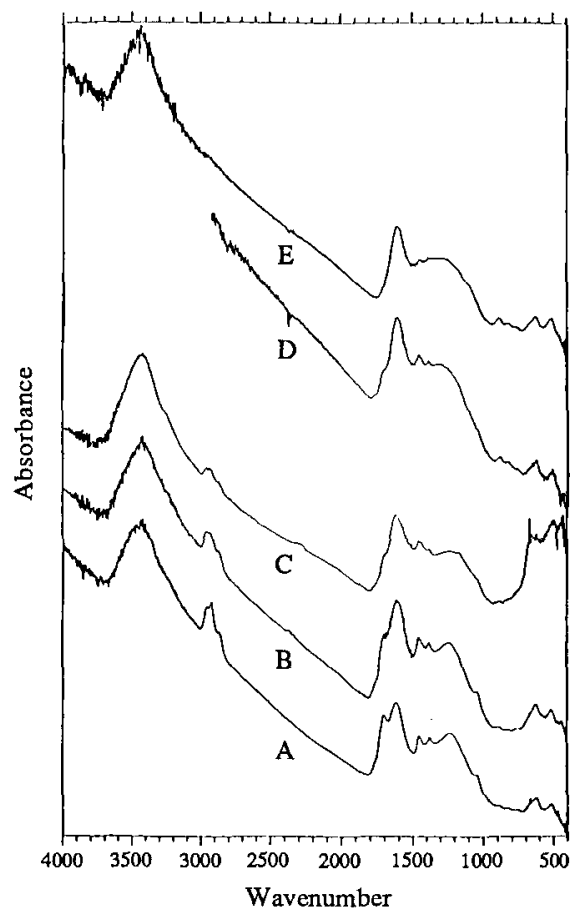

Figure 6. Spectra of acid insoluble residue of the Orgueil $\mathrm{C} 1$ carbonaceous chondrite: (a) absorbance, $\mathrm{x} 1.13$, and the residue after heating in vacuum to temperatures of (b) $195 \mathrm{C}, \mathrm{x} 1.63$ (c) $300 \mathrm{C}, \mathrm{x}$ 5.63 (d) $415 \mathrm{C}, \mathrm{x} 1$; and (e) $500 \mathrm{C}, \mathrm{x} 1.75$. The broad feature at $3450 \mathrm{~cm}-1$ is due to $\mathrm{H}_{2} \mathrm{O}$ from humidity trapped in the KBr sample matrix (Wdowiak et al. 1988).

\subsection{COMPARISONS WITH CARBONACEOUS SOLIDS}

The measured gas abundances and the near cosmic total $\mathrm{C} / \mathrm{O}$ found by the spacecraft dust detectors show that carbon in Comet Halley is mainly in dust. Most carbon in comets, like the carbon in the interstellar medium, appears to be sequestered in relatively refractory 
carbonaceous solids.

Clues to the nature and identity of cometary organics may lie in solar system solids such as carbonaceous chondrites or interplanetary dust particles. Laboratory syntheses are also important to the search. Comparisons with these substances are still in an early phase; we will summarize them only briefly here. Clearly, spectral and physical comparisons are subject to uncertainties brought about by possible alteration of the compounds in the coma. The particles intercepted by the spacecraft must be fairly refractory (Jessberger et al. 1989), but the survivability of the carbonaceous compounds remains a caveat in the interpretations.

There are interesting resemblances between organic extracts of meteorites and of the comet emitter as shown in Figure 6 (cf. Wdowiac et al. 1988; Cruikshank et al.1988; Hayatsu et al. 1977). Meteorites contain many complex organic compounds, including insoluble polymers that are difficult to characterize, but that consist partly of cross-linked aromatic chains (Anders et al. 1973; Hayatsu et al. 1977). The meteorite organics also have strong bands in the 4- to $15-\mu \mathrm{m}$ spectral region. Such bands would be diagnostic if sufficient sensitivity can be achieved to detect them against the dust background in comets (Section 4.4).

Interplanetary dust particles also have a $3.4-\mu \mathrm{m}$ carbonaceous feature that has structure somewhat similar to that of the comet band (Swan et al. 1987; Walker 1988). These organics have not yet been analyzed in detail, because of the small amounts of material that are available and because terrestrial contamination may be present.

There is one apparent difference between comet and interplanetary dust or meteorite spectra. Comets have more emission shortward of $3.4 \mu \mathrm{m}$ than is present in either interplanetary dust or meteorite spectra. This may point to a larger, or perhaps different, complement of aromatic compounds in comets - if the emission mechanisms are not fooling us.

Infrared spectra of compounds synthesized in the laboratory show qualitative, but by no means exact, spectral similarities to those in comets (cf. Greenberg 1982, Chyba and Sagan 1987a,b). Before the Halley apparition, several investigators inferred that comets would contain carbonaceous material (cf. the reviews in Comets, Wilkening 1982). To what extent the cometary data support specific models is still open (Greenberg 1987; Brownlee 1988; Kissel and Krueger 1987).

\subsection{COMPARISON OF COMET AND INTERSTELLAR CARBON COMPOUNDS}

Comparison of infrared spectra, comets and interstellar, could supply insights into both and into the possibility of a comet-interstellar dust connection (Tokunaga and Brooke 1990; Knacke 1989). This involves comparing two unknowns because the composition of interstellar dust is also poorly understood. Indeed, the nature of the carbon compounds is a 
particularly difficult problem in interstellar chemistry (Irvine and Knacke 1988).

Interstellar infrared spectra in the 3- to $4-\mu \mathrm{m}$ region point to at least three distinct components of carbonaceous dust. These include emissions peaking at $3.29 \mu \mathrm{m}$ (Figure $7 \mathrm{~b}$ ), absorption at $3.4 \mu \mathrm{m}$ in the spectrum of the Galactic Center (Figure 7c), and an absorption near $3.4 \mu \mathrm{m}$ in molecular clouds (Figure $7 \mathrm{~d}$ ). The latter absorption has been most extensively studied in the Galactic Center, but there there are possible detections in other sources also (Butchart et al. 1986; Topia et al. 1990). Carbon is a major component of interstellar dust (Tielens and Allamandola 1987).

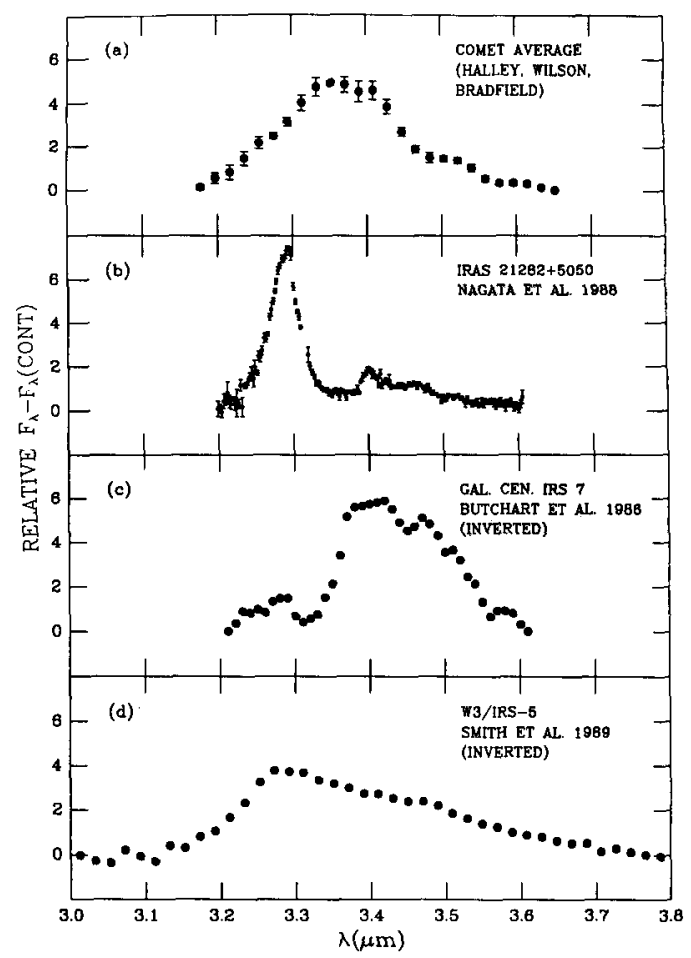

Figure 7. (a) Average of the three comet spectra in Figure 2. (b) Spectrum of emission by small particles near HII regions (c) Absorption (inverted) to the Galactic Center. (d) Absorption (inverted) in a molecular cloud (Tokunaga and Brooke 1989).

Figure 7 includes a spectrum of the "average" comet $3.4-\mu \mathrm{m}$ emission, derived by summing the data in Figure 2. Comparison with the spectra in Figure 7 shows immediately that the interstellar bands differ from the comet emission. The comets, HII regions, diffuse clouds, and molecular clouds each have characteristic, and different, band shapes. Evidently varied carbonaceous materials form in these environments, not surprising in view of the wide 
ranges of temperatures and physical conditions. Also, different emission mechanisms can account, at least partly, for these differences.

Some detailed features of the bands are significant. The $3.29-\mu \mathrm{m}$ emission occurs in or near HII regions, usually with weaker emission extending to $3.5 \mu \mathrm{m}$. Similar emission seems to occur in the wing of the comet band (Section 4.3). The origin of this interstellar band is controversial. Carbonaceous materials including polycyclic aromatic hydrocarbons (PAHs), a composite formed from a discharge containing methane ("quenched carbonaceous composite", QCC), and hydrogenated amorphous carbon (HAC) are among proposed identifications (see reviews in Polycyclic Aromatic Hydrocarbons and Astrophysics, Leger et al. 1987). While none of these substances give perfect spectral fits to interstellar spectra, all show some impressive correspondences. The proposed materials may, in fact, include similar compounds, especially aromatics to which the $3.29-\mu \mathrm{m}$ emission is quite specific. The detection of the $3.29-\mu \mathrm{m}$ emission in the interstellar dust and emission near this wavelength in comets suggests that aromatic ring compounds may be widespread in carbonaceous solids.

The cometary 3.4- to $3.6-\mu \mathrm{m}$ band structure, which is diagnostic of partially saturated compounds (Section 4.3), resembles (but again is not identical to) molecular cloud absorptions and the Galactic Center absorber (Smith et al. 1989; Knacke and McCorkle 1987). The structure is weak or absent in HII region spectra.

The occurrence of these features may reflect the stability of carbon compounds (Knacke et al. 1987). Aromatics are very stable and apparently survive the harsh conditions near HII regions. The less stable compounds or groups, with signatures at $3.4 \mu \mathrm{m}$ and longward, occur in the more benign environments of molecular clouds. Since comet spectra contain evidence for aromatics as well as for saturated groups, both evidently survived the early solar system and the Oort cloud.

These conclusions are obviously qualitative and based on perceived similarities in the spectra. For more detailed discussions of possible interstellar - comet connections, we refer the reader to discussions by Greenberg (1982), Encrenaz et al. (1988), Knacke (1989), Tokunaga and Brooke (1990), and references in these papers.

\subsection{COMPLEX COMPOUNDS AND SPECTRAL FITS}

There are similarities between the 3.4- $\mu \mathrm{m}$ spectra of biological species and the Halley spectra (Hoyle and Wickramasinghe 1987). We believe these similarities arise because both materials contain $\mathrm{C}-\mathrm{H}, \mathrm{O}-\mathrm{H}$, and probably N-H groups. As pointed out above, the infrared absorption bands of gases and solids are the result of near-neighbour interactions, usually involving motions of a few atoms. Inferring large-scale, complicated structures (such as of bacteria which contain billions of atoms) from infrared bands is highly problematical. One can establish the presence of $\mathrm{C}$-H groups, but not the large scale-structure and complexity of the compounds. For other aspects of this clebate, see Kissel and Krueger (1987), Chyba and Sagan (1987b), and Greenberg and Zhao (1988). 
We emphasize, however, that the same problem must be faced when making any spectral comparison, such as comparisons with ostensibly more probable solids from the solar system or the interstellar medium as we have done above. Spectral matches of complex carbonaceous compounds risk being accidental when carried much beyond identification of functional groups, particularly when there is only one band available. We have argued the negative above, that is, that since the bands are not identical, the substances are not either. The converse, that matching bands mean the same compounds, does not follow.

\section{Conclusions and Future Observations}

Progress in understanding the nature of carbonaceous compounds in comets, the interstellar medium, and the solar system is rapid now. Not much is known about the complexities of the comet carbonaceous materials, nor can we say very much definite about their origins. Carbonaceous substances occur in comets, the solar system, and interstellar dust, but there are real differences among these materials. What are these differences telling us about the origins and histories? We are still searching for definitive evidence for direct connections between comets and interstellar material. The connection seems very plausible and observations point to interstellar grains as comet constituents (Geiss 1988, Whipple 1987), but what exactly in a comet is pristine interstellar matter, what originated in the solar nebula and where, and what is a combination of both remains to be worked out.

The history of investigations of carbonaceous material in meteorites, coals, and kerogens may indicate the magnitude of the problem of the comet carbonaceous material. There are still interesting and unanswered questions about them after more than a century of study which included ready laboratory access. Comets are not likely to be easier.

The advent of array detectors in infrared astronomy will give large, sometimes orders of magnitude, improvements in spectroscopy. Missions such as ISO and SIRTF, as well as airborne platforms like the KAO and SOFIA, can exploit these instrumental advances with high sensitivity and in spectral regions that are inaccessible to ground-based instruments. Large telescopes equipped with array detectors are critical for the higher resolving power (2000) that is needed to make progress in understanding the carbonaceous substances. Nevertheless, the diagnostic capability of infrared spectroscopy has limitations when complex substances are involved. In situ and sample return missions such as CRAF and ROSETTA will be critical to clarifying the nature of the carbonaceous substances.

We thank T.Y Brooke and A.T. Tokunaga for providing data prior to publication and for valuable comments. Comet research at Stony Brook was supported by NSF grant AST 8414825 and NASA grants NGT-33-015-803 and JPL956274. 


\section{References}

A'Hearn, M.F., et al. (1986). 'Cyanogen Jets in Comet Halley,' Nature, 324, 649-651.

A'Hearn, M.F., and Feldman, P.D. (1980). 'Carbon in Comet Bradfield 1979l,' Astrophys. J., 242, L187-L190.

A'Hearn, M.F., Feldman, P.D., and Schleicher, D.G. (1983). 'The Discovery of $\mathrm{S}_{2}$ in Comet IRAS-Araki-Alcock (1983d),' Astrophys. J., 274, L99-L103.

Allamandola, L. (1988). Private communication.

Allen, D.A., and Wickramasinghe, D.T. (1987). 'Discovery of Organic Grains in Comet Wilson,' Nature, 329, 615-616.

Allen, M., et al. (1987). 'Evidence for Methane and Ammonia in the Coma of Comet P/Halley;' Astron. Astrophys., 187, 502-512.

Anders, E., Hayatsu, R., and Studier, M.H. (1973). 'Organic Compounds in Meteorites,' Science, $182,781-790$.

Azoulay, G., and Festou, M.C. (1986). 'The Abundance of Sulphur in Comets,' in C.-I. Lagerkvist et al. (eds.), Asteroids, Comets, Meteors II, Uppsala University Press, Uppsala, pp. 273-277.

Baas, F., Geballe, T.R., and Walther, D.M. (1986). 'Spectroscopy of the 3.4-Micron Emission Feature in Comet Halley,' Astrophys. J., 311, L97-L101.

Becklin, E.E., and Westphal, J.A. (1966). 'Infrared Observations of Comet 1965f,' Astrophys. J., 145, 445-453.

Bellamy, L.J. (1975). 'The Infrared Spectra of Complex Molecules,' Vol. I, Chapman and Hall, London.

Biermann, L., Giguere, P.T., and Huebner, W.F. (1982). 'A Model of a Comet Coma With Interstellar Molecules in the Nucleus,' Astron. Astrophys., 108, 221-226.

Bisikalo, D.V., Repin, S.V., and Strelnitskiz, V.S. (1986). Astron. Tsirk. No. 1450.

Bockelee-Morvan, D. (1987). 'A Model for the Excitation of Water in Comets,' Astron. Astrophys., 181, 169-181.

Bockelee-Morvan, D., and Crovisier, J. (1987). 'The 2.7- $\mu \mathrm{m}$ Water Band of Comet P/Halley: Interpretation of Observations by an Excitation Model,' Astron. Astrophys., 187, 425-430.

Bockelee-Morvan, D.M., et al. (1987). 'Molecular Observations of Comets P/GiacobiniZinner 1984 and P/Halley 1982i at Millimeter Wavelengths,' Astron. Astrophys., $180,253-262$.

Bregman, J.D., Campins, H., Witteborn, F.C., Wooden, D.M., Rank, D.M., Allamandola, L.J., Cohen, M., and Tielens, A.G.G.M. (1987). 'Airborne and Groundbased Spectrophotometry of Comet P/Halley From 15 to 13 Micrometers,' Astron. Astrophys., 187, 616-620.

Brooke, T.Y., and Knacke, R.F. (1986). 'The Nucleus of Comet P/Arend-Rigaux,' Icarus, 67, $80-87$.

Brooke, T.Y., and Tokunaga, A.T. (1990). 'Comparison of the 3.4- $\mu \mathrm{m}$ Emission Feature in Comets,' Icarus, in press.

Brooke, T.Y., Knacke, R.F., Owen, T.C., and Tokunaga, A.T. (1989). 'Spectroscopy of Emission Features Near 3 Microns in Comet Wilson (19861),' Astrophys. J., 336, 971-978. 
Brooke, T.Y., Tokunaga, A.T., Knacke, R.F., Owen, T.C., Mumma, M.J., Reuter, D., and Storrs, A.D. (1989). 'Detection of the 3.4- and 2.8- $\mu \mathrm{m}$ Emission Features in Comet Bradfield (1987s), 'Icarus, in press.

Brownlee, D.E. (1988). 'A Comparison of Halley Dust With Meteorites, Interplanetary Dust, and Interstellar Grains,' in M.S. Hanner (ed.), Infrared Observations of Comets Halley and Wilson and Properties of the Grains, NASA Conf. Pub. 3004, pp. 66-67.

Butchart, I., McFadzean, A.D., Whittet, D.C.B., Geballe, T.R., and Greenberg, J.M. (1986). 'The Micron Spectroscopy of the Galactic Center Source IRS 7,' Astron. Astrophys., 154, L5-L7.

Campins, H., et al. (1986). 'Airborne Spectrophotometry of Comet Halley From 5 to 9 Microns,' in Proc. 20th ESLAB Symposium on the Exploration of Halley's Comet, ESA SP-250, pp. 121-124.

Chin, G., and Weaver, H.A. (1984). 'Vibrational and Rotational Excitation of CO in Comets: Nonequilibrium Calculations,' Astrophys. J., 285, 858-869.

Chyba, C., and Sagan, C. (1987a). 'Infrared Emission by Organic Grains in the Coma of Comet Halley,' Nature, 330, 350-353.

Chyba, C., and Sagan, C. (1987b). 'Cometary Organics But No Evidence for Bacteria,' Nature, 329, 208.

Chyba, C., Sagan, C., and Mumma, M.J. (1989). 'The Heliocentric Evolution of Cometary Infrared Spectra: Results for an Organic Grain Model,' Icarus, in press.

Clark, B.C., Mason, L.W., and Kissel, J. (1987). 'Systematics of the "CHON" and Other Light-Element Particle Populations in Comet P/Halley,' Astron. Astrophys., 187, 779-784.

Colangeli, L., Schwehm, G., Busoletti, E., Fonti, S., Blanco, A., and Orofina, V. (1989). 'The Unidentified IR Bands in Laboratory, Interstellar Medium, and in Comets,' in 22nd ESLAB Conference, Infrared Spectroscopy in Astronomy, ESA SP-290, in press.

Combes, M., et al. (1986). 'Infrared Sounding of Comet Halley From VEGA 1,' Nature, $321,266-268$.

Combes, M., et al. (1988). "The 2.5-12 $\mu \mathrm{m}$ Spectrum of Comet Halley From the IKS-VEGA Experiment,' Icarus, 76, 404-436.

Crovisier, J. (1984). 'The Water Molecule in Comets: Fluorescence Mechanisms and Thermodynamics of the Inner Coma,' Astron. Astrophys., 13, 361-372.

Crovisier, J. (1987). 'Rotational and Vibrational Synthetic Spectra of Linear Parent Molecules in Comets,' Astron. Astrophys. Suppl., 68, 223-258.

Crovisier, J., and Bourlot, J. (1983). 'Infrared and Microwave Fluorescence of Carbon Monoxide in Comets,' Astron. Astrophys., 123, 61-66.

Crovisier, J., and Encrenaz, Th. (1983). 'Infrared Fluorescence of Molecules in Comets: The General Synthetic Spectrum,' Astron. Astrophys., 126, 170-182.

Cruikshank, D.P., and Brown, R.H. (1987). 'Organic Matter on Asteroid 130 Elektra,' Science, 238, 183-284.

Danks, A.C., Encrenaz, Th., Bouchet, P., LeBertre, T., and Chalabaev, A. (1987). 'The Spectrum of Comet P/Halley From 3.0 to $4.0 \mu \mathrm{m}$,' Astron. Astrophys., 184, 329332.

Delsemme, A.H. (1982). 'Chemical Composition of Cometary Nuclei,' in L.L. Wilkening (ed.), Comets, University of Arizona Press, Tucson, pp. 85-130. 
Despois, D., Crovisier, J., Bockelee-Morvan, D., Schram, J., Forveille, J., and Gerard, E. (1986). 'Observations of Hydrogen Cyanide in Comet Halley,' Astron. Astrophys., 160, L11-L12.

D'Hendecourt, L.B., Allamandola, L.J., Grim, R.J.A., and Greenberg, J.M. (1986). "TimeDependent Chemistry in Dense Molecular Clouds. II. Ultraviolet Photoprocessing and Infrared Spectroscopy of Grain Mantles,' Astron. Astrophys., 158, 119-134.

Dischler, B., Bubenzer, A., and Kordl, P. (1983). 'Bonding in Hydrogenated Hard Carbon Studied by Optical Spectroscopy,' Solid State Comm., 48, 105-108.

Drapatz, S., Larson, H.P., and Davis, D.S. (1987). 'Search for Methane in Comet P/Halley,' Astron. Astrophys., 187, 497-501.

Eberhardt, P., et al. (1987). 'The CO and $\mathrm{N}_{2}$ Abundance in Comet P/Halley,' Astron. Astrophys., 187, 481-484.

Emerich, C., et al. (1987). 'Temperature and Size of the Nucleus of Comet P/Halley Deduced From IKS Infrared Vega 1 Measurements,' Astron. Astrophys., 187, 839842.

Encrenaz, Th., Crovisier, M., Combes, M., and Crifo, J.F. (1982). 'A Theoretical Study of Comet Halley's Spectrum in the Infrared Range,' Icarus, 51, 660-664.

Encrenaz, Th., D'Hendecourt, L., and Puget, J.L. (1988). 'On the Interpretation of the 3.23.5 Micron Emission Feature in the Spectrum of Comet Halley: Abundances in P/Halley and in Interstellar Matter,' Astron. Astrophys., 207, 162-173.

Encrenaz, Th., Puget, J.L., Bibring, J.P., Combes, M., Crovisier, J., Emerich, C., D'Hendecourt, L., and Rocard, F. (1987). 'On the Interpretation of the $3 \mu \mathrm{m}$ Emission Feature in the Spectrum of Comet Halley: Abundances in Comet Halley and in Interstellar Matter,' in Symposium on the Diversity and Similarity of Comets, ESA SP-278, pp. 369-376.

Feldman, P.D. (1982). 'Ultraviolet Spectroscopy of Comae,' in L.L. Wilkening (ed.), Comets, University of Arizona Press, Tucson, pp. 461-479.

Feldman, P.D., A'Hearn, M.F., Festou, M.C., McFadden, L.A., Weaver, H.A., and Woods, T.N. (1986). 'Is $\mathrm{CO}_{2}$ Responsible for the Outbursts of Comet Halley?', Nature, 324, $433-436$.

Festou, M.C., et al. (1986). 'IUE Observations of Comet Halley During the Vega and Giotto Encounters,' Nature, 321, 361-363.

Gatley, I., Becklin, E.E., Neugebauer, G., and Werner, M.W. (1974). 'Infrared Observations of Comet Kohoutek (1973f),' Icarus, 23, 561-565.

Geiss, J. (1988). 'Composition in Halley's Comet: Clues to Origin and History of Cometary Matter,' in G. Klare (ed.), Reviews in Modern Astronomy, Vol. 1, Springer-Verlag, Berlin.

Giguere, P.T., and Huebner, W.F. (1978). 'A Model of Cometary Comae I. Gas-Phase Chemistry in One Dimension,' Astrophys. J., 223, 638-654.

Greenberg, J.M. (1982). 'What Are Comets Made of? A Model Based on Interstellar Dust,' in L.L. Wilkening (ed.), Comets, University of Arizona Press, Tucson, pp. 131-163.

Greenberg, J.M., and Zhao, N. (1988). Letter, Nature, 331, 124.

Hanner, M.S., and Tokunaga, A.T. (1990). 'Infrared Techniques for Comet Observations,' in this volume.

Hanner, M.S., et al. (1985). 'The Dusty Coma of Periodic Comet Churyumov-Gerasimenko (1982 VIII),' Icarus, 64, 11-19. 
Hanner, M.S., Aitken, D.K. Knacke, R., McCorkle, S., Roche, P.F., and Tokunaga, A.T. (1985). 'Infrared Spectrophotometry of Comet IRAS-Araki-Alcock (1983d): A Bare Nucleus Revealed?', Icarus, 62, 97-109.

Hanner, M.S., Knacke, R.F., Sekanina, Z., and Tokunaga, A.T. (1985). 'Dark Grains in Comet Crommelin,' Astron. Astrophys., 152, 177-181.

Haser, L. (1957). 'Distribution d'Intensité Dans la Tête d'une Comète,' Bull. Acad. Roy. Belgique, Classe des Sciences, 43, 740-750.

Hayatsu, R., Matsuoka, S., Scott, R.G., Studier, M.H., and Anders, E. (1977). 'Origin of Organic Matter in the Early Solar System - VII. The Organic Polymer in Carbonaceous Chondrites,' Geochim. Cosmochim. Acta., 41, 1325-1339.

Hoyle, F., and Wickramasinghe, N.C. (1987). 'Organic Dust in Comet Halley,' Nature, 328, 117.

Huebner, W.F. (1987). 'First Polymer in Space Identified in Comet Halley,' Science, 237, 628-630.

Huebner, W.F., Boice, D.C., and Sharp, C.M. (1987). 'Polyoxymethylene in Comet Halley,' Astrophys. J., 320, L49-L52.

Huebner, W.F., Giguere, P.T., and Slattery, W.L. (1982). 'Photochemical Processes in the Inner Coma,' in L.L. Wilkening (ed.), Comets, University of Arizona Press, Tucson, pp. 496-515.

Huebner, W.F., Snyder, L.E., and Buhl, D. (1974). 'HCN Emission of Comet Kohoutek (1973f),' Icarus, 23, 580-584.

Irvine, W., and Knacke, R.F. (1989). 'The Chemistry of Interstellar Gas and Grains,' in S.K. Atreya, J.B. Pollack, and M.S. Matthews (eds.), Origin and Evolution of Planetary and Satellite Atmospheres, University of Arizona Press, Tucson, pp. 3-34.

Jessberger, E.K. (1990). 'Chemical Properties of Cometary Dust,' in this volume.

Jessberger, E.K., Kissel, J., and Rahe, J. (1989). 'The Composition of Comets,' in S.K. Atreya, J.B. Pollack, and M.S. Matthews (eds.), Origin and Evolution of Planetary and Satellite Atmospheres, University of Arizona Press, Tucson, pp. 167-191.

Johnson, T.V., Brown, R.H., and Pollack, J.B. (1987). 'Uranus Satellites: Densities and Composition,' J. Geophys. Res., 92, 14, 884-894.

Kawara, K., Gregory, B., Yamamoto, T., and Shibai, H. (1989). 'Infrared Spectroscopic Observation of Methane in Comet P/Halley,' Astron. Astrophys., 207, 174-181.

Keller, H.U., and Lillie, C.F. (1974). 'The Scale Length of $\mathrm{OH}$ and the Production of $\mathrm{H}$ and $\mathrm{OH}$ in Comet Bennett (1970 II),' Astron. Astrophys., 34, 187-196.

Keller, H.U., et al. (1986). 'First Halley Multicolor Camera Imaging Results From Giotto,' Nature, 321, 320-326.

Kerridge, J.F., and Chang, S. (1985). 'Survival of Interstellar Matter in Meteorites: Evidence From Carbonaceous Material,' in D.C. Black and M.S. Matthews (eds.), Protostars and Planets II, University of Arizona Press, Tucson, pp. 738-771.

Kim, S.J., and A'Hearn, M.F. (1989). 'Sulfur Compounds in Comets,' Icarus, in press.

Kissel, J., and Krueger, F.R. (1987). 'The Organic Component in Dust for Comet Halley as Measured by the PUMA Mass Spectrometer on Board Vega 1,' Nature, 326, 755760.

Kissel, J., et al. (1986). 'Composition of Comet Halley Dust Particles From Vega Observations,' Nature, 321, 280-282.

Knacke, R.F. (1989). 'Comet Dust Connections With Interstellar Dust,' in L.J. Allamandola and A.G.G.M. Tielens (eds.), D. Reidel Publ. Co., Dordrecht, in press. 
Knacke, R.F., and McCorkle, S. (1987). 'Spectroscopy of the Kleinmann-Low Nebula: Scattering in a Solid Absorption Band,' Astron. J., 94, 972-976.

Knacke, R.F., Brooke, T.Y., and Joyce, R.R. (1986). 'Observations of 3.2-3.6 Micron Emission Features in Comet Halley,' Astrophys. J., 310, L49-L53.

Knacke, R.F., Brooke, T.Y., and Joyce, R.R. (1987). 'The 3.2-3.6 $\mu \mathrm{m}$ Emission Features in Comet P/Halley: Spectral Identifications and Similarities,' Astron. Astrophys., $187,625-628$.

Knacke, R.F., Kim, Y.H., Noll, K.S., and Geballe, T.R. (1988). 'Search for Interstellar Methane,' in R.L. Dickman et al. (eds.), Molecular Clouds in the Milky Way and External Galaxies, Springer-Verlag, Berlin, pp. 180-181.

Koike, C., Hasegawa, H., and Manabe, A. (1980). 'Extinction Coefficients of Amorphous Carbon Grains From $2100 \AA$ to $340 \mu \mathrm{m}$,' Astrophys. Space Sci., 67, 495-502.

Korth, A., et al. (1989). 'Probable Detection of Organic-Dust-Borne Aromatic $\mathrm{C}_{3} \mathrm{H}_{3}{ }^{+}$Ions in the Coma of Comet Halley,' Nature, 337, 53-55.

Krankowsky, D., et al. (1986). 'In Situ Gas and Ion Measurements at Comet Halley,' Nature, 321, 326-329.

Krishna Swamy, K.S., Sandford, S.A., Allamandola, L.J., Witteborn, F.C., and Bregman, J.D. (1988). 'A Multicomponent Model of the Infrared Emission From Comet Halley,' Icarus, 75, 351-370.

Larson, H.P., Weaver, H.A., Mumma, M.J., and Drapatz, S. (1989). 'Airborne Infrared Spectroscopy of Comet Wilson (19861) and Comparisons With Comet Halley,' Astrophys. J., 1106-1114.

Leger, A., and d'Hendecourt, L. (1987). 'Identification of PAHs in Astronomical IR Spectra-Implications,' in A. Leger et al. (eds.), Polycyclic Aromatic Hydrocarbons and Astrophysics, D. Reidel Publ. Co., Dordrecht, pp. 223-254.

Leger, A., et al. (eds.) (1987). Polycyclic Aromatic Hydrocarbons and Astrophysics, D. Reidel Publ. Co., Dordrecht.

Lewis, J.S., and Prinn, R.G. (1980). 'Kinetic Inhibition of $\mathrm{CO}$ and $\mathrm{N}_{2}$ Reduction in the Solar Nebula,' Astrophys. J., 238, 357-364.

Maas, R.W., Ney, E.P., and Woolf, N.F. (1970). 'The 10-Micron Emission Peak of Comet Bennett 1969i,' Astrophys. J., 160, L101-L104.

Millis, R.L., A'Hearn, M.F., and Campins, H. (1988). 'An Investigation of the Nucleus and Coma of Comet P/Arend-Rigaux,' Astrophys. J., 324, 1194-1209.

Mitchell, D.L., et al. (1987). 'Evidence for Chain Molecules Enriched in Carbon, Hydrogen and Oxygen in Comet Halley,' Science, 237, 626-628.

Moroz, V.I., et al. (1987). 'Detection of Parent Molecules in Comet P/Halley From the IKSVega Experiment,' Astron. Astrophys., 187, 513-518.

Mumma, M.J., and Reuter, D.C. (1989). 'On the Identification of Formaldehyde in Halley's Comet,' preprint.

Mumma, M.J., Weaver, H.A., Larson, H.P., Davis, D.S., and Williams, M. (1986). 'Detection of Water Vapor in Halley's Comet,' Science, 232, 1523-1528.

Ney, E.P. (1982). 'Optical and Infrared Observations of Bright Comets in the Range $0.5 \mu \mathrm{m}$ to $20 \mu \mathrm{m}$,' in L.L. Wilkening (ed.), Comets, University of Arizona Press, Tucson, pp. 323-340.

Oishi, M., Okuda, H., and Wickramasinghe, N.C. (1978). 'Infrared Observations of Comet West (1975n). II. A Model of the Cometary Dust,' Publ. Astron. Soc. Japan, 30, 161-171. 
Prinn, R.G., and Lewis, J.S. (1980). 'Kinetic Inhibition of $\mathrm{CO}$ and $\mathrm{N}_{2}$ Reduction in the Solar Nebula,' Astrophys. J., 238, 357-364.

Rouxhet, P.G., Robin, P.L., and Nicaise, G. (1980). 'Characterization of Kerogens and of 'Their Evolution by Infrared Spectroscopy,' in B. Durand (ed.), Kerogen, Editions Technip., Paris, pp. 163-190.

Sagdeev, R.Z., et al. (1986). 'Television Observations of Comet Halley From Vega Spacecraft,' Nature, 321, 262-266.

Sandford, S.A., and Allamandola, L. (1988). 'The Condensation and Vaporization Behavior of $\mathrm{H}_{2} \mathrm{O}$ :CO Ices and Implications for Interstellar Grains and Cometary Activity,' Icarus, 76, 201-204.

Schloerb, F.P., Kinzel, W.M., Swade, D.A., and Irvine, W.M. (1987). 'Observations of HCN in Comet P/Halley,' Astron. Astrophys., 187, 475-480.

Scoville, N., Kleinmann, S.G., Hall, D.N.B., and Ridgway, S.T. (1983). 'The Circumstellar and Nebular Environment of the Becklin-Neugebauer Object: $\lambda=2-5$ Micron Spectroscopy,' Astrophys. J., 225, 201-224.

Sellgren, K. (1984). 'The Near-Infrared Continuum Emission of Visual Reflection Nebulae,' Astrophys. J., 277, 623-633.

Smith, R.G., Sellgren, K., and Tokunaga, A.T. (1989). 'Absorption Features in the 3 Micron Spectra of Protostars,' Astrophys. J., 344, 413-426.

Snyder, L.E., Palmer, P., and de Pater, I. (1989). 'Radio Detection of Formaldehyde Emission From Comet Halley;' Astron. J., 97, 246-253.

Swan, P., Walker, R.M., and Wopenka, B. (1987). '3.4 $\mu \mathrm{m}$ Absorption in Interplanetary Dust Particles: Evidence of Indigenous Hydrocarbons and a Further Link to Comet Halley,' Meteoritics, 510-511.

Swings, P., and Page, T.L. (1950). 'The Spectrum of Comet Bester (1947k),' Astrophys. J., $111,530-534$.

Tapia, M., Persi, P., Roth, M., and Ferrari-Toniolo, M. (1990). 'Three-Micron Spectroscopy of Three Highly Reddened Field Stars,' Astron. Astrophys., in press.

Tielens, A.G.G.M., and Allamandola, L.J. (1987). 'Composition, Structure, and Chemistry of Interstellar Dust,' in D.J. Hollenbach and H.A. Thronson, Jr. (eds.), Interstellar Processes, D. Reidel Publ. Co., Dordrecht, pp. 397-469.

Tokunaga, A.T., and Brooke, T.Y. (1990). 'On Testing the Hypothesis via Infrared Spectroscopy That Comets Originated Directly From the Interstellar Medium,' Icarus, in press.

Ulich, B.L., and Conklin, E.J. (1975). 'Discovery of $\mathrm{CH}_{3} \mathrm{CN}$ in Comets,' Nature, 248, $121-$ 122.

Walker, R.M. (1988). 'Comparison of Laboratory Determined Properties of Interplanetary Dust With Those of Comet Halley Particles: What Are Comets Made of?', in M. Hanner (ed.), Infrared Observations of Comets Halley and Wilson and Properties of the Grains, NASA Conf. Pub. 3004, pp. 53-63.

Wdowiak, T.J., Flickinger, G.C., and Cronin, J.R. (1988). 'Insoluble Organic Material of the Orgueil Carbonaceous Chondrite and the Unidentified Infrared Bands,' Astrophys. J., 328, L75-L79.

Weaver, H.A., and Mumma, M.J. (1984). 'Infrared Molecular Emissions From Comets,' Astrophys. J., 276, 782-797.

Whipple, F.L. (1989). 'Comets in the Space Age,' Astrophys. J., 341, 1-15. 
Wickramasinghe, D.T., and Allen, D.A. (1986). 'Discovery of Organic Grains in Comet Halley, Nature, 324, 44-46.

Wilkening, L.L. (ed.) (1982). Comets, University of Arizona Press, Tucson.

Woods, T.N., Feldman, P.D., Dymond, K.F., and Sahnow, D.J. (1986). 'Rocket Ultraviolet Spectroscopy of Comet Halley and Abundance of Carbon Monoxide and Carbon,' Nature, 324, 436-438.

Wyckoff, S. (1982). 'Overview of Comet Observations,' in L.L. Wilkening (ed.), Comets, University of Arizona Press, Tucson, pp. 3-55.

Yamamoto, T. (1982). 'Evaluation of Infrared Line Emission From Constituent Molecules of Cometary Nuclei,' Astron. Astrophys., 109, 326-330. 